\title{
Traditional Health Practitioners' practices and the sustainability of extinction-prone Traditional Medicinal Plants
}

by

\section{MAGORO MADIMETJA DAVID}

submitted in part fulfilment of the requirements for the degree of

MASTERS OF HUMAN ECOLOGY

in the subject

HUMAN ECOLOGY

at the

UNIVERSITY OF SOUTH AFRICA

SUPERVISOR: Dr M A. Mearns

CO-SUPERVISOR: Dr M A. Masoga

JUNE 2008 


\begin{abstract}
For centuries Traditional Health Practitioners (THPs) used their indigenous knowledge (IK) in conserving medicinal plants and environments to maintain sustainability. With the rapid environmental, social, economic and political changes occurring in many areas inhabited by rural people exist the danger that the loss of biodiversity from habitat destruction and unsustainable harvesting practices will result in some species becoming extinct.
\end{abstract}

The main aim of the study was to determine the natural habitat of extinctionprone traditional medicinal plants combining the insight of THPs with an ultimate goal of guiding research for the conservation, propagation and cultivation of traditional medicinal plants. Despite problems, opportunities and challenges expressed and identified by THPs, the analysis of data from interview schedule and personal observations, show that the THPs' practices are shaped by historical processes and local cultural values, social norms and their management strategies that are influenced by a broad range of factors. 
Stud: 36370770

\section{DECLARATION}

"I hereby declare that the thesis submitted for the degree Master in Human Ecology, at University of South Africa, is my own original work and has not previously been submitted to any other institution of higher education. I further declare that all sources cited or quoted are indicated and acknowledged by means of a comprehensive list of references"

Madimetja D. Magoro

Date 


\section{DEDICATION}

I would like to dedicate this study to my wife Lehlokwa Veronicca Magoro (Modipadi) and my three daughters Khutšišo Nancy (Hunadi), Mothekgi Euginia (Mahlako) and Tetelo Goodness (Mangakane) and my son Modisha Phasoane (Ngwato) for being so supportive and understanding. To them I would like to say "Modimo le badimo ba ba hlahle maphelong a bona - May God and Ancestors guide them through their lives". 


\section{ACKNOWLEDGEMENTS}

I wish to acknowledge the Agricultural Research Council (ARC) for the financial support that enabled me to undertake this study. My sincere gratitude and appreciation go to Dr M.A Mearns, my promoter for her support and guidance and Dr M.A Masoga for overseeing progress in our work.

In addition, I would like to express my sincere gratitude to the following individuals:

- Mrs M. Masekoameng, Lecturer at UNISA for motivation and encouragement.

- Miss C. Malotja, Junior Lecturer at UNISA for assisting me logistically.

- Mr J. Rathelele, Technical Admin assistant from UNISA for providing me with information.

- Dr M.A Masoga, Senior Researcher from Development Bank of Southern Africa for his advice early on during the study.

I am indeed grateful and would like to remember and thank the friendly and kind Traditional Health Practitioners from Nkumpi Lepelle and Marble Hall municipality, who participated in the workshop and field visits, answered my numerous questions, and shared their experiences with me with great patience. Finally, thanks must be given to all the staff of University of South Africa, Department of Agricultural, Animal Health and Human Ecology who supported my study. 
Abstract

Declaration

Dedication. .ii

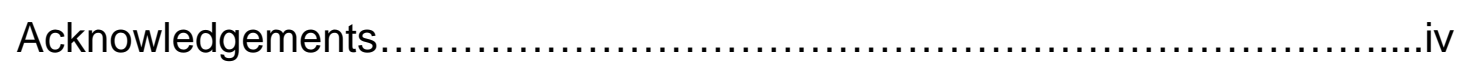

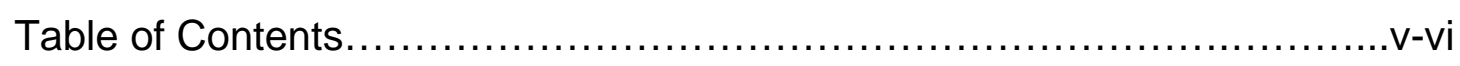

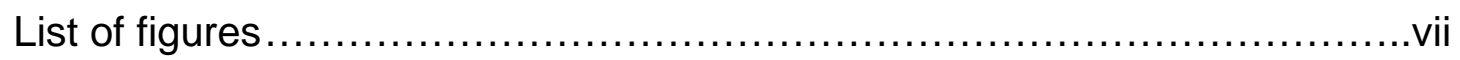

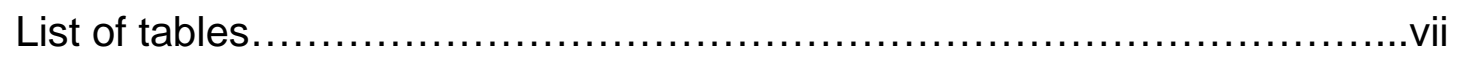

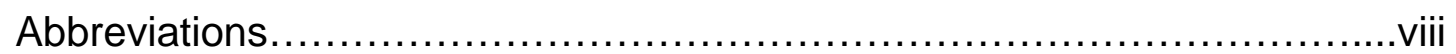

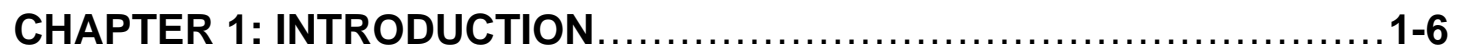

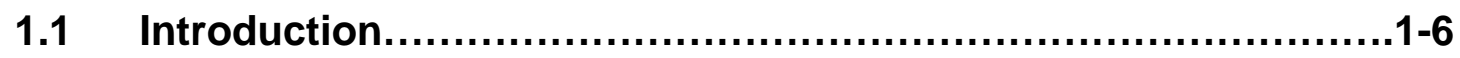

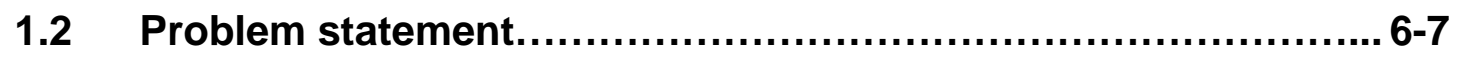

$1.3 \quad$ Research questions................................................. 7

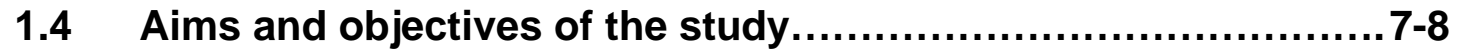

CHAPTER 2: LITERATURE REVIEW.................................... 9

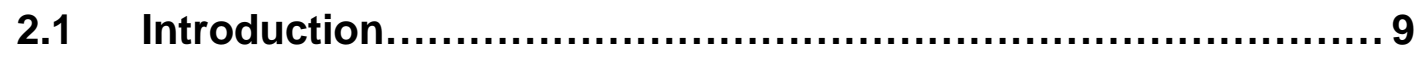

2.2 Indigenous knowledge and traditional medicine in Africa........9

2.2.1 Indigenous knowledge.........................................10-12

2.2.1.1 Indigenous knowledge paradigm........................12-15

2.2.1.2 Importance of indigenous knowledge...................15-20

2.2.2 What is traditional medicine?..............................................20-22

2.2.2.1 Importance of traditional medicine in Africa...............22-25

(i) Precolonial situation.................................... 25 


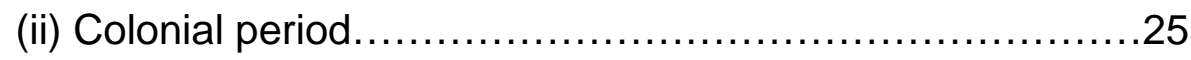

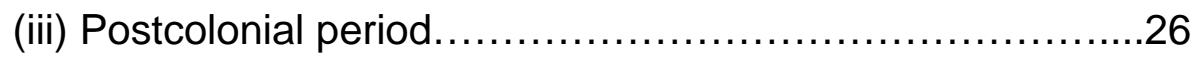

2.2.2.2 Traditional medicine from medicinal plants perspective....28-29

2.2.3 Traditional medicine in South Africa............................. 29-33

2.2.3.1 Economic and trade issues...........................34-36

CHAPTER 3: RESEARCH APPROACH.......................................

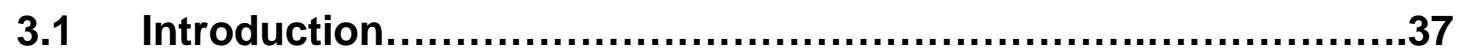

3.2 Study area.............................................................

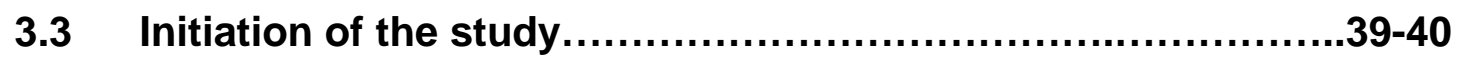

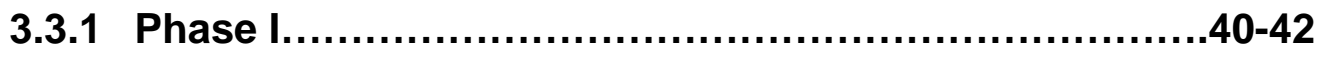

3.3.2 Phase II.....................................................42-44

CHAPTER 4: RESULTS AND DISCUSSIONS $\ldots \ldots \ldots \ldots \ldots \ldots \ldots \ldots \ldots \ldots \ldots . \ldots$

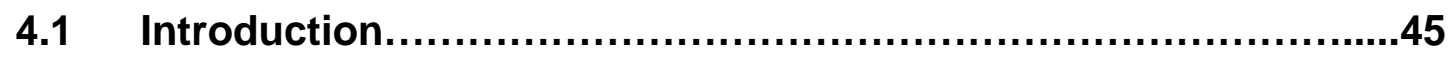

4.2 Documentation of scarce medicinal plants...................45-50

$4.3 \quad$ Harvesting practices.............................................50-53

4.4 The depletion of medicinal plants observed.....................53-54

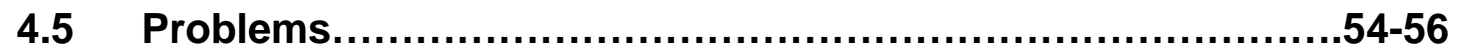

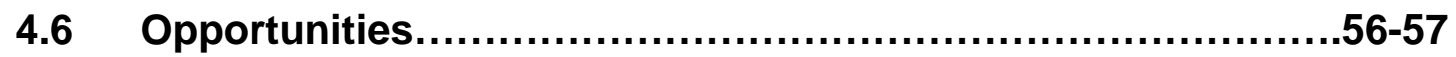

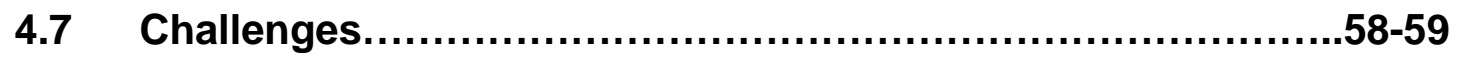

CHAPTER 5: CONCLUSIONS AND RECOMMENDATIONS.................60

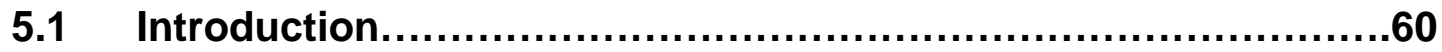

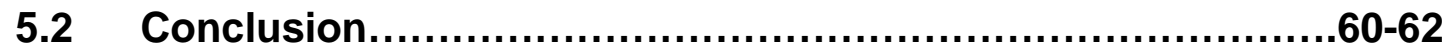

$5.3 \quad$ Recommendations....................................................62-64

$5.4 \quad$ The challenges ahead..............................................6

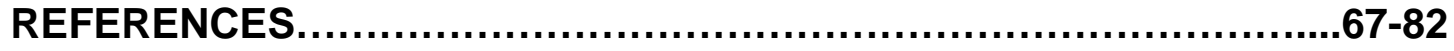




\section{LIST OF FIGURES}

FIGURE 3.1 Map of Limpopo province (Marula Marketing, 2007)...........38

FIGURE 3.3 THPs' who attended the workshop at Magatle Village from $22^{\text {nd }}$

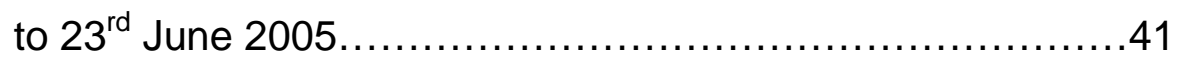

FIGURE 4.1 Some of THPs concerned about scarce medicinal plants......46

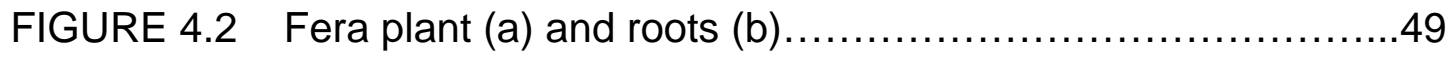

FIGURE 4.3 Madi a phalane plant (a) and mooka tree (b) .................49

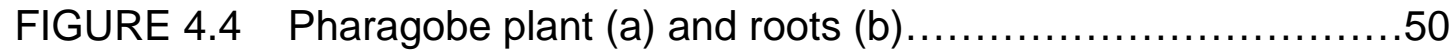

FIGURE 4.5 A tree showing signs of bark harvested on the eastern side of

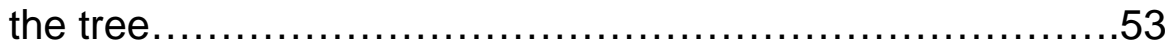

\section{LIST OF TABLES}

TABLE 4.1 List of medicinal plants in terms of scarcity .47 


\section{ABBREVIATIONS}

ARC Agricultural Research Council

CBNRM Community Based Natural Resource Management

CSIR Council for Scientific and Industrial Research

DST Department of Science and Technology

IK Indigenous Knowledge

IUCN International Union for Conservation of Nature

MRC Medical Research Council

PROMETRA Promotion of Traditional Medicine

PROTA Plant Resources of Tropical Africa

SANBI South African National Biodiversity Institute

THPs Traditional Health Practitioners

UNESCO United Nations Educational Scientific and Cultural Organisation

WCMC World Conservation Monitoring Centre

WHO World Health Organisation 


\section{CHAPTER 1}

\subsection{INTRODUCTION}

Traditional medicine has a long history. The World Health Organization (WHO, 2000:1) defines it as the sum total of the knowledge, skills and practices based on the theories, beliefs and experiences indigenous to different cultures, whether explicable or not, used in the maintenance of health, as well as in the prevention, diagnosis, improvement or treatment of physical and mental illnesses. Practices of traditional medicine vary greatly from country to country and are influenced by factors such as culture, history, personal attitudes and philosophy (WHO, 2000:2). The theory and application of traditional health practices are quite different from those of conventional medicine.

The historical use of many practices of traditional medicine, including experience passed on from generation to generation, has demonstrated the safety and efficacy of traditional medicine. In Uganda, traditional medical care, used by over $80 \%$ of the population, involves a series of activities, order of knowledge, beliefs, and customs, is organised and employed by practitioners to generate beneficial effects of diagnosis and prevention to eliminate imbalances in the physical, psychological or social well-being of people (Kerwigi, 1998:9).

In 1997, a study was initiated in South Africa by Botha et al (2003) to determine the extent of trade in medicinal plants in the Lowveld (the low lying plains to the east of the KwaZulu Natal and Mpumalanga provinces), and to 
investigate socio-economic factors influencing trade and resource management. According to Botha et al (2003:3), trade was not as extensive in the Lowveld region of Mpumalanga and KwaZulu Natal province as in major urban markets such as Durban or the Witwatersrand, either in terms of the quantity, number or range of species sold, or the numbers of people relying on the trade for an income. Botha et al (2003:12) also indicated that in markets in Mpumalanga province, 176 species were identified (71\% of the vernacular names encountered in the market place), representing 69 plant families. According to Botha et al (2003:12) 70 different species were also identified in Limpopo (84\% of the vernacular names encountered in the market place), representing 40 families. Imports were significant in Mpumalanga (33\% of the plants on offer), mainly from Mozambique. Their study showed considerable local variation and complexities in the harvesting and marketing of medicinal plants, with both a national and an international dimension. This dual spatial scale presents both opportunities and challenges in the management of these plants, which need to be addressed simultaneously, particularly with respect to research requirements and development of predictive models and capacity.

Colonial powers and historically restrictive government structures in South Africa have played an overpowering role on practices of Traditional Health Practitioners (THPs) and their patients and have disrupted the distinction between superstition and indigenous technological practices of THPs (e.g Witchcraft suppression Act of 1957). In Africa the pre-colonial era was dominated by traditional leadership (chiefs and elders) that enforced good management through sanctions, customary laws, taboo systems (diila), and 
effective control systems for community compliance. The colonial approach however forcefully removed communities out of resource management and created reserves and parks. "This had profound negative effects on the development of South Africa's economy and society, resulting in the distortion of social, cultural and economic development of the vast majority of its people" (Department of Science and Technology (DST), 2004:13).

Traditional medicine and traditional agriculture represent significant economic activity in South Africa. However, the knowledge systems of local communities played an important role in managing natural resources. The knowledge of THPs pertaining to medicinal plants and their environment sustained their practices. Indigenous knowledge (IK) can be a fundamental starting point in conservation strategies. They can be more effective when there is additional assurance that land tenure and management regimes support the role of communities and THPs. In characterizing the medicinal properties of plants, indigenous taxonomies often ascribe identity and spiritual values to plants (Posey, 2000). Therefore IK still plays a pivotal role in sustainable livelihoods of a significant proportion of the South African population (DST, 2004:14).

According to WHO (2002) and the Medical Research Council (MRC) (1997) traditional medicine form an integral part of the culture and more than $80 \%$ of black South Africans go to a THPs when sick. The South African National Biodiversity Institute (SANBI) (2005), indicates about $70 \%$ of the South African population that depends on traditional medicines derived from indigenous plants and animals. This may lead to the assumptions from the 
perception that people utilize traditional medicine as a second choice. The percentage is used as an estimate by different researchers and might be higher due to the reversed stigmatization and marginalization of the latter in the country.

In recent years the government has realized the need to recognize and formalize traditional healing e.g South Africa has founded the Institute for African Traditional Medicines and Traditional Health Practitioners Act 35 of 2004 which shows that the government supports THPs and their medicines. Despite the marginalization of traditional medicine practiced in the past, the attention currently given by the government to widespread healthcare application has given a new impetus to research investment and design of programmes in the field. The Indigenous Knowledge Systems Policy in South Africa provide practical measures for the development of services provided by IK holders and practitioners, with a particular focus on traditional medicine, and also including areas such as agriculture, indigenous languages and folklore (DST, 2004:13).

In conducting research and evaluating traditional medicine, knowledge and experience obtained through long history of established practices by THPs should be respected. The main interest of research in South Africa lies with the rich sources of medicinal plants that are found and used in South Africa. Much of the research has been primarily academic and has not considered the knowledge of THPs. The main factor is time that has transpired for local practices adoption and transformation on incremental basis to suit the social and economic needs of a local community. The improvements on the 
practices have been integrated in the norms and values of the local people through traditional systems over time. As a result, the practices are associated with the local communities that use them to manage their environment and natural resources. It is therefore important to conduct research which will ultimately benefit THPs in South Africa.

Research activities have been carried out to address the conservation and sustainable use of traditional plant genetic resources (their ecological requirements) and traditional knowledge holders' contributions were not integrated and reflected in the research. The demand by most of the people in South Africa for medicinal plants has been met by indiscriminate harvesting of spontaneous flora including those in the forests (Cunningham, 1991). A survey conducted in South Africa by Mander (1998:2) also indicated that as many as 4000 tons of plant materials from the wild, harvested from 700 medicinal plants species, were traded per year in KwaZulu Natal Province, which led to the extinction of wild ginger/serokolo (Siphonochilus aethiopicus) and pepper-bark tree (Warburgia salutaris) outside protected areas. As a result, many plant species have become extinct and some are endangered, thereby threatening their genetic and species diversity and affecting the ecological stability of the habitats in which they are found. However, the loss of biodiversity from habitat destruction and unsustainable harvesting practices often means that an entire range of medicines will no longer be available to both rural or urban THPs, and increasing pressure on diminishing wild stocks of plants in conservation taboos being ignored and ultimately lost. 
Accompanying the loss of habitat is the loss of associated indigenous knowledge. In villages, THPs harvest plant materials from the local environment in ways that ensure sustainable supply. However, THPs are often no longer the harvesters of the plants and this poses a very serious problem on collection and usage. Habitat destruction appears to be the most important of all the factors like propagation and cultivation. The primary cause of species loss at local, regional and global level is through habitat loss and it is harmful not only to a single species, but to whole communities and ecosystems. The remaining habitat is also fragmented by habitat loss. This is because edges of habitats are strongly affected by their surrounding matrix (Rossetto, 2003).

\subsection{PROBLEM STATEMENT}

Local people are not likely to readily accept new doctrines thrust upon them in the form of modern environmental conservation strategies, which most of them do not understand (Mavi \& Shava. 1997). For example, certain conservation techniques are implicit in the traditional methods of obtaining medicines from plants. THPs have voiced serious concerns regarding extinct medicinal plants and environmental degradation (Manaswe, 2005). Traditionally, rural African communities have relied upon the spiritual and practical skills of the THPs whose botanical knowledge of plant species and their ecology and scarcity are invaluable. Given the lack of documents regarding the knowledge of THPs about conservation of traditional medicines in their local environment, this subject has never been fully explored. It is 
therefore necessary that people and THPs understand traditional medicine from a traditional ecological perspective and the knowledge to protect threatened species.

Therefore the research was initiated to outline the problems, opportunities and challenges in harvesting extinction-prone traditional medicinal plants in various agro ecological environments and natural habitats. The study was conducted at Magatle and Klopper villages, Capricorn and Greater Sekhukhune District under Marble Hall and Nkumpi Lepelle municipality in Limpopo Province, in order to determine the challenges faced by THPs concerning the harvesting of extinction-prone medicinal plants in the area.

\subsection{RESEARCH QUESTIONS}

a) Main research question:

- What are the problems, opportunities and challenges in harvesting traditional medicinal plants?

b) Sub questions:

- Which medicinal plants are extinct-prone in the various agro-ecological environments of the study areas?

- What causes loss of habitat in the study areas?

\subsection{Aim and objectives of the study}

The study aimed to determine the natural habitat of extinction-prone traditional medicinal plants combining the insights of THPs with an ultimate 
goal of guiding research for the conservation, propagation and cultivation of traditional medicines. The research entailed the following specific objectives:

- To document the specific habitat where extinction-prone medicinal plants originate

- To determine local traditions regarding harvesting and conservation of traditional medicinal plants

- To identify the problems, opportunities and challenges faced by THPs in the study area regarding the harvesting of traditional medicinal plants and especially extinction-prone plants.

The chapters report on the research in the following manner:

Chapter 2: A literature review reporting on indigenous knowledge and traditional medicinal plants from an African and South African perspective.

Chapter 3: reports on the two phases through which the research was conducted.

Chapter 4: Analyses the qualitative research findings that was gathered during both Phases I and II of the data collection process.

Chapter 5: summarises and concludes the discussions and provides certain recommendations that were identified during research. 


\section{CHAPTER 2}

\section{LITERATURE REVIEW}

\subsection{INTRODUCTION}

This chapter describes the literature review, which was directed by the central concepts in the study. The literature review was narrowed down to the concepts of traditional medicine and indigenous knowledge in Africa. The literature was studied in order to position traditional medicine and IK within the THPs' perspectives. Other areas explored included the value of traditional medicine and IK.

\subsection{Indigenous knowledge and traditional Medicine in Africa}

IK of people is varied around the world, but there are consistent patterns in the way knowledge is acquired. IK is intensely local in its factual information and has a long term information base. From an African context, IK has been ignored and maligned by western people during colonial periods as becomes evident in the discussions raised in paragraph 2.2.1. IK is useful as a basis for self-sufficiency and determination because people are familiar with indigenous practices and technologies. In this section, indigenous knowledge and traditional medicine will be defined and discussed. 


\subsubsection{Indigenous knowledge}

The meaning of the term 'indigenous knowledge' is by no means clear to everyone, especially now that it is rapidly coming into more current use in development circles. There is a wide range of alternatives employed by the various writers, as they discuss what this field entails and the possible approaches. Nonetheless, they all share a certain common idiom and address the same broad issues. IK in Africa is an embodiment of different modes of thought and "epistemology" as shared by many authors such as (Warren, 1991a; Haverkort et al., 1991, Rajasekaran, 1993; Grenier, 1998 and Battiste \& Henderson, 2000). All the variations of the terms for IK are to be found in the literature, such as rural people's knowledge, indigenous technical knowledge, traditional environmental knowledge, local knowledge, traditional knowledge (Chambers; 1979; Geertz, 1983; Thrupp, 1989; Butler \& Waud, 1990; Warren 1991a; Haverkort et al., 1991).

The term IK is defined as a systematic body of knowledge acquired by local people through the accumulation of experiences, informal experiments and intimate understanding of the environment in a given culture (Rajasekaran \& Whiteford, 1992: 237-247; Warren, 1991a). According to Grenier (1998:1), IK is "the unique traditional, local knowledge existing within and developed around the specific conditions of women and men indigenous to a particular geographic area. It further read as the sum total of the knowledge and skills which people in a particular geographical area possess, and which enable them to get the most out of their natural environment". Warren (1991a) 
defines IK as the knowledge that people in a given community has developed over time and continues to develop. According to Haverkort et al (1991:3), IK is the actual knowledge of a given population that reflects the experiences based on traditions and includes more recent modern technologies. Moreover, these people are well informed about their own situations, their resources, what works and don't work, and how one change impacts on other parts of their system (Butler \& Waud, 1990:77-98).

IK and resource use practice has been defined as a cumulative body of knowledge and beliefs handed down through generations by cultural transmission about relationships of living beings, (including human) with one another and with the environment (Gadgil et al., 1993:151-156). According to Battiste and Henderson (2000:41), IK is a complete knowledge system with its own epistemology, philosophy, and scientific and logical validity which can only be understood by means of pedagogy traditionally employed by people themselves. IK is stored in peoples' memories and activities and it's expressed in the form of stories, songs, folklore, proverbs, dances, myths, cultural values, beliefs, rituals, community laws, local language and taxonomy, agricultural practices, equipment, materials, plant species, and animal breeds. Indigenous forms of communication and organisation are vital to local-level decision making process and to the preservation, utilization, development and spread of IK (Rajasekaran, 1993; Grenier, 1998).

$\mathrm{IK}$ is a pluralistic approach to conservation and management of natural resources. According to Warren (1991b), it is also a subjective understanding 
and social construction process, which consists of cosmos (world views), praxis, corpus and institution to guide human action by adaptive process. Warren (1991b) further indicates that the primary dimension of difference and uniqueness seems to lie in an organic relationship between the local community and its knowledge. IK is therefore, of crucial significance if one wishes to introduce a cost-effective, participatory and sustainable development process (Warren, 1991a). Similarly when development pressures impact significantly on community resource use and management, such as the case with medicinal plant harvesting, IK should not only be considered, but should be driving the challenges in terms of the future sustainability of a community resource.

\subsubsection{Indigenous Knowledge paradigm}

One of the foundations of the African concept of harmony and peace rests upon the basic African cultural world-view of the philosophy of participation and integration. There is no drastic distinction between man and nature. The theory of knowledge that the African cultural experience project is that the world is centered upon the self and that man lives in a personal world view. The African culture does not assume that reality can be perceived through reason alone. There are other modes of knowing, such as, imagination, intuitive experience, and personal feelings.

There are hundreds of district ethnic groups and languages in Africa, with more than 250 groups in Nigeria alone, each with its unique culture and 
traditional practices matched by a correspondingly greater diversity in genetic resources and ecosystems (Nnadozie, 2004:9). Nnadozie (2004) further indicate that most common attributes of all peoples of Africa is the almost dependence on, or rather interdependence with, nature and natural resources for survival and existence. Over centuries Africa has been exploited in various ways, including the wholesale plundering of Africa's human resources in the slave trade and the exploitation by colonialists of Africa's mineral resources, genetic diversity, and cultural treasures (Lor \& Britz 2004:16). According to Masoga (2004:iv), this implied that Africa, particularly South Africa, experienced a period of knowledge paralysis, the impact of which went as far as forcing Africans to denigrate who they are and ignore the 'baggage' that brought them into contention with exogenous knowledge systems.

Today the exploitation of Africa's IK has come to the foreground. In support of Lor and Britz (2004), this knowledge, the product of millennia during which African communities came to terms with and adapted to their often harsh environment, was initially disregarded as unscientific folklore. Today, bioprospectors are visiting rural communities, making friends with the "locals", questioning them about their use of plants in traditional medicine, and taking samples back to the North where the active constituents are isolated in the laboratory and then patented. Over the last decade several studies have been carried out highlighting the potential of IK in rural development. The emphasis in most cases has been on agriculture, agro-forestry, livestock farming and ecological and natural resource management (Warren, 1991a; Warren \& Rajasekaran, 1993:8-10). 
The ignorance towards and the marginalisation of IK in the nineteenth century colonialism and social science has been well documented by authors such as Jackson (1987), Warren (1989); Posey and Dutfield (1996), Rajasekaran (1993), and Slikkerveer (1989). According to Warren (1989) "various studies that depicted local communities and their knowledge as primitive, simple and static are now counted by a rapidly expanding database generated by both biological and social scientists that describes the complexity and sophistication of many indigenous natural resource management systems". This historic neglect has contributed to the decline of IK systems, through lack of use and application. IK of medicine has suffered greater stigmatization through missionaries, political agents who successfully outlawed ceremonies being practiced.

The legacy is still evident because many medical professionals are still sceptical. On the other hand IK has permitted its holders to exist in 'harmony' with nature, allowing them to use it sustainably; it is seen as especially pivotal in discussions of sustainable resource use (Compton, 1989:113; Flora \& Flora, 1989:7-32; Ghai \& Vivian, 1989; Moock, 1992:1-10; Sen, 1992; Inglis, 1993). It was within this knowledge that the THPs and people in the community are able to collect, process and trade medicinal plants because they form part of their natural vegetation.

The THPs and communities in various regions are able to distinguish between edible and non-edible plants. They have not learned this from formalised institutions of learning but via indigenous forms of tuition and knowledge 
transfer. They have obtained a substantial part of their income from the sale of medicinal plants and traditional medicinal treatment. The culture and knowledge systems of THP's and their institutions provided frameworks, ideas, guiding principles, procedures and practices that are of value to the social, economic and environmental resilience in Africa and other parts of the world. It is therefore essential that knowledge of the people in the continent should not be subsumed by the domination of cultures that notoriously foster inequality and materialism.

\subsubsection{Importance of Indigenous knowledge}

IK can be a fundamental starting point in conservation strategies. Communities can be more effective in conserving natural resources when there is additional assurance that land tenure and management regimes support their role and knowledge in conservation. The value of IK to modern science and technology is indisputable. Scientists, medical researchers, nutritionists and pharmaceutical companies are exploiting rural communities' knowledge of plants, animals and the environment for mainly commercial gain. IK has two powerful advantages over outside knowledge - it has little or no cost and is readily available (Kothari, 1995).

IK technologies are socially desirable, economically affordable, sustainable and involve minimum risk to communities, and above all, they are used to conserve resources. In other words, IK provide a basis for problem solving strategies for local communities. According Dewalt (1994) features of IK 
which are relevant to conservation and sustainable development are as follows:

- "Locally appropriate: IK represents a way of life that has evolved with the local environment, so it is specifically adapted to the requirements of local conditions;

- Restraint in resource exploitation: production is for subsistence needs only; only what is needed for immediate survival is taken from the environment;

- Diversified production systems: there is no overexploitation of a single resource: risk is often spread out by utilizing a number of subsistence strategies;

- Respect for nature: a 'conservation ethic' often exists. The land is considered sacred, humans are dependent on nature for survival, all species are interconnected;

- Flexible: IK is able to adapt to new conditions and incorporate outside knowledge;

- Socially responsibility: there are strong family and community ties, and with them feelings of obligation and responsibility to preserve the land for future generations".

In characterising the medicinal properties of plants, indigenous taxonomies often ascribe to identify spiritual value to plants (Posey, 2000). The customary institutions play important roles in regulating access to land and natural resources through social and cultural sanctions. 
In South Africa restrictions placed by traditional community leaders and enforced by headmen and traditional community policemen have reduced commercial exploitation of local traditional plant resources. Traditional mechanisms have shown that the rural communities have their own ways to explain the world and to protect their own resources. With cultural change, increased entry into the cash economy and rising unemployment, however, these controls are breaking down (Cunningham \& Mbenkum, 1993). According to Getz, et al (1999:1855) there was an emerging trend that community-based natural resource management (CBNRM) or cultural based natural resource management, which allows local people to take responsibility, acknowledge their knowledge and processes of conversation and the sustainable use of natural resources and finally, build competence of "civil scientists" at the village level with accountable knowledge system for indigenous and scientific society.

The 1992 Convention on Biological Diversity is key international protocols for not only protecting and sharing of biological resources, but also addressing issues of IK. It calls for the respect, to promote the wide application of IK, as well as to encourage equitable sharing of benefits from IK. There are emerging indigenous movements both in the developed and developing countries for advocacy of IK and traditional resource rights (Posey \& Dutfield, 1996:303). Since the 1992 Convention, global interest in the wider use and application of traditional peoples knowledge, innovation and practices has accelerated (Posey, 2004). Besides the Convention, the United Nations 
Educational, Scientific and cultural Organisation (UNESCO) has taken steps to protect the cultural dimension of IK including traditional medicine, among other types of knowledge. According to Correa (2004), the UNESCO Conference held in Paris on $29^{\text {th }}$ September to $17^{\text {th }}$ October 2003 adopted the international Convention on the preservation of the intangible cultural heritage, as a complement to the convention concerning the protection of the world cultural and natural heritage. On a very positive note, the convention recognises that states have sovereign rights over their natural resources, and that terms and conditions for access to these materials are within the domain of national legislation. Therefore, the South African government developed their National Environmental Management: Biodiversity Act of 2004 dealing with regulations on bio-prospecting, access and benefit-sharing.

The Act aims to provide for the use of indigenous biological resources in a sustainable manner; fair and equitable sharing among stakeholders of benefits arising from bio-prospecting involving indigenous biological resources (Department of Environmental Affairs and Tourism, 2004). According to the regulation of the act published in February 2008, it will regulate permit system that applies to bio-prospecting involving indigenous biological resources or export from the Republic of any indigenous biological resources for the purpose of bio-prospecting or any kind of research and set out the contents of, the requirements and criteria for benefit-sharing and material transfer agreement (Department of Environmental Affairs and Tourism, 2008). The act was to be implemented by the Department of Environmental Affairs and Tourism as of the $1^{\text {st }}$ of April 2008. The International Biological Diversity 
proclaimed by United Nations is celebrated every $22^{\text {nd }}$ day of May each year to increase understanding and awareness of biodiversity issues. It is evident that biodiversity issues are receiving much needed attention and in terms of its relation to IK. Many IK centres are being established in the continent, not only showing how important $\mathrm{IK}$ is, but also as a means of formalising research endeavours related to IK practices.

As a result of this, the social survival welfare strategies are totally focused on local, diverse and fragile resource base. Hence there emerged a system, which individually or jointly strengthened the ecosystem-social system links and contributed to the natural resource-friendly management systems. According Farooguee and Saxen (1996:75-80), the local control over the local resources and the greater autonomy, due to absence of external impositions led to the adoption of social responses tuned to minimise the pressure on resources through social and institutional fora. In this research more emphasis is on the practices of THPs facing challenges of the socio-cultural and economic environment.

The apartheid regime has a long history of allowing the exploitation of the knowledge of THPs for their own interests or vested interest in the form of pharmaceutical industries to manipulate THPs intellectual property rights evident in the commercial exploitation of buchu, aloe vera, devils' claw, African potato, and hoodia. It is becoming more acceptable now regarding holistic perspectives by the South African government that communities should embrace their cultural heritage regarding the utilization of traditional 
medicines. The demise of the past regime has prevented communities access to potential natural resources. Conservation of natural resources was associated with protected areas that served the privileged elite, and restricted access to natural resources often involving the forced relocation of black communities (Wynberg, 2002). The emphasis here is that the use of IK in biodiversity conservation in theory finds one of its strengths. Maintenance of rules based on tradition is stronger and more community owned than government rules. This offers an opportunity to involve people in biodiversity conservation using their IK systems. Therefore, the effects of $\mathrm{IK}$ on biodiversity conservation are real and should not be underestimated. IK is context specific and is validated by community/local use. What works successfully in one location or for another community may not for another, because in a community there are diverse group of people. In the study, the reflection is that there are local experts in the rural areas whom the researchers can learn from in terms of knowledge and experiences pertaining to what is $\mathrm{IK}$ and traditional medicine.

\subsubsection{What is traditional medicine?}

According to WHO $(2000 ; 1)$ the definition of traditional medicine may be summarised as the sum total of all the knowledge, skills and practices based on the theories, beliefs, and experiences indigenous to different cultures, whether explicable or not used in the maintenance of health as well as in the prevention, diagnosis, improvement and elimination or treatment of physical, mental or social imbalance. This is relying exclusively on practical experience 
and observation handed down from generation to generation, whether verbally or in writing. Traditional medicine might also be considered as a solid amalgamation of dynamic medical know-how and ancestral experience.

Traditional medicine, since times immemorial, has been used in virtually all cultures as a source of health-care. According to Hoareau and Dasilva (1999), traditional medicine in several developing countries, using local traditions and beliefs, is still the mainstay of health care. Africa is a rich source of medicinal plants and traditional medicine is diverse and pluralist in nature.

Traditional medicine is the oldest most tried and tested form of medicine (WHO, 2000). In a sense it is degrading to refer to it as an "alternative" to western medicine, since it forms the basis of all medicine - conventional drugs, homeopathic medicine, Chinese medicine etc. It is the original medicine, the mother of all remedies used today. If it is accepted that Africa according to anthropological researchers (Aiello \& Collard, 2001; Balter \& Gibbons, 2000; Clarke \& Tobias, 1995; Clarke, 1999; Murdock, 1959; Richmond \& Strait, 2000) is the cradle of humankind, then the use of herbs is as old as humakind itself and therefore it stands to reason that African traditional medicines and practices are indeed the oldest, most tried and tested.

Traditional medicine is more holistic in nature because it addresses many issues related to socio-cultural and economic environment. During the apartheid era scepticism about traditional customs and beliefs abound, and 
research on traditional medicine as opposed to western medicine defined traditional medicine as 'alternative' and 'contemporary'. These views of traditional medicine being the 'alternative' has been regarded by THPS as offensive and traditional medicine is deeply rooted in specific socio-cultural context which varies from one community to another. It is important therefore to note that there are as many traditional medicines as there are communities.

African traditional medicine is thus a distillation of African cultures, but the spirit that moves it is that shared by all forms of medicine, since the fear of disease and death and the need for food and health have led men in every age and clime to seek assistance from all that nature can offer them (WHO, 1983:25) citing Kouamaré (1978).

\subsubsection{Importance of Traditional Medicine in Africa}

In sub-Saharan Africa, traditional medicine has been for centuries and still the most affordable and accessible health care system. In an African context, the resolution on promoting the dramatic decline in mortality, the increase in life expectancy and the eradication of smallpox are highlights of the success (Zhang, 2004:3). In Africa the resolution on "Promoting the Role of Traditional Medicine in Health Systems: A strategy for the African Region", adopted by the fiftieth meeting of the World Health Organisation's (WHO's) Regional Committee for Africa in August 2000, states that the African member states are aware that about 80 percent of the regions' population depends on traditional medicine for its health care needs. Traditional health care practices 
existed in South Africa and Africa long before colonization. Over centuries, African people have developed a wide variety of indigenous technologies in harmony with nature. A long history of use of many practices of traditional medicine, including experience passed on from generation to generation, has demonstrated the safety and efficacy of traditional medicine (WHO, 2000:1).

In the past, modern science has considered methods of traditional knowledge as primitive and during the colonial era traditional medicinal practices were often declared as illegal by the colonial authorities (Rukangira, 2001). This was echoed to destroy and suppress the values, culture and traditional medicine. Culture has been mentioned on several occasions in this chapter reiterating that culture plays an important role regarding the knowledge and practices of rural communities and THPs.

The above-discussed reliance on traditional medicine can be attributed to a number of factors, most importantly, relatively good accessibility, local availability, affordability and existence of local knowledge and expertise among communities. According to Marshall (1998), there is a low proportion of allopathic doctors per unit population and clinics are few and remotely situated, given an example in the Machakos district of Kenya, the ratio of doctors to patient is $1: 7,142$, while the ratio of THPs to patient was $1: 378$. In Uganda, the ratio of THPs to population was estimated as 1:200 and 1:400, while the ratio of allopathic doctors to the population was 1:20, 000 (WHO, 2002:2). In South Africa the ratio of THPs is $1: 1,639$ to $1: 700$ in relation to 1:1,200 for allopathic doctors (IK Notes, 2003). These figures have increased 
drastically in favour of THPs because the burden has already been placed on the population and on government resources by the HIVIAIDS pandemic. This further weakens the affordability of allopathic healthcare.

Traditional medicine does not only play an important role in healthcare, it is also important as a source of nutrition. Medicinal plants are used in soups, tonics, as appetizers, energy boosters, in teas, flavourings, in aromatherapy and as chewing sticks (Maundu et al., 2001). In hindsight and considering how the knowledge of traditional medicine has grown in some parts of Africa, it is clear that successive cultural and philosophical systems have played positive roles. The general opinion is that African traditional medicine did not lead to any discovery in the medical sciences yet examples such as buchu, aloe vera, devils claw, african potato, hoodia amongst others abound. African traditional medicine had existed before the introduction of western medicine, and suited the needs of African culture (Makinde, 1988:91). Therefore, theories and practices of medicine have a cultural dimension. Makinde (1988) further stresses that a people's belief, faith and religion have much to do with the acceptance of the efficacy or otherwise of any particular system of medicine that need no philosophical justification.

According to Gasengayire (1999:121), during the colonial era, the practice of traditional medicine was stigmatized and discouraged by both religious missionary and colonial authorities. During the past centuries, clinics or hospitals were not available in rural areas and people survived through usage of traditional medicine exemplifying the importance of traditional medicine. 
African medicine has produced a number of THPs who has studied through years of training and experience to recognise the symptoms of sickness and disease and to apply effective remedies through knowledge of medicinal herbs and other traditional means. The secretive nature of their knowledge, however, has made the principle and practice of traditional medicine inaccessible to curious minds. It was important to protect the knowledge pertaining to traditional medicine from the exploiters. Every culture has either intuitive or pragmatic reasons for holding on to a belief. In the case of traditional medicine, there are intuitive and pragmatic grounds for believing in its efficacy. Bannerman et al (1983:25) has outlined three periods in the development of traditional medicine in the African continent.

(i) Precolonial situation

This was the period where traditional health practitioners and traditional midwives practised their arts freely and were sole guardians of the peoples' health. Knowledge was passed on by initiation within the same family or at most within the same clan. There was no record of the practices.

\section{(ii) Colonial period}

This period entailed the introduction of the colonial power's own civilisation, religion, medicine and technology. The primary aim of the modern or western medicine was to look after the interests of the colonists in the urban centres. During this period traditional medicine, which was repressed by the 
authorities, moved underground. The practitioners and the users made sure that such activities were conducted without the knowledge of the authorities. It was therefore important for the THPs to protect their knowledge from colonists by giving them incorrect information about medicinal plants. To add to WHO's reflections, the authorities at that time were interested in the healing powers of medicinal plants and this resulted in the implementation of the witchcraft act that suppressed THPs and communities as indicated in chapter 1.

(iii) Postcolonial period

The independence era brought a gradual change in the above situation. Traditional medicine recovered its former status in many countries and there were several attempts to bring about recognition, official status, harmonization and collaboration.

WHO (1983) reflects on what happened during these periods. THPs practices continued to flourish in the rural areas, explaining why currently, many African states, have the aim to unify and uplift African traditional medicine. Some African states have taken the leading role in conducting African traditional medicine conferences and celebrations such as African Day of Traditional Medicine which is held every year in August aiming at informing policy formulation. An organisation called PROMETRA (Promotion of Traditional Medicine) International is constituted of 21 chapters. PROMETRA indicates "Chapters" as the preferred word to be used instead of organisations. There are chapters in Uganda, Tanzania, South Africa, Senegal, Ghana, Guinea, 
Kenya, Gabon, Togo, Ivory Coast, Cameroon, Benin, Bakino Faso and Mali. These chapters are aimed at promoting the interests of Africans and supports WHO (2000) when describing traditional medicine as one of the surest means to achieve total health care coverage of the world's population. Mostly the African countries mentioned above are endowed with vast resources of medicinal and aromatic plants and the plants have been used over the millennia for the welfare of humans and their environment.

The age-old practices are presently continually being supported due to large proportion of people in Africa living in rural areas. The "WHO's Traditional Medicine Strategy 2002-2005" includes one of its objectives on the "protection and preservation of indigenous traditional medicinal knowledge relating to health". It is also indicated that WHO will "help countries to develop strategies to protect their indigenous traditional medicine knowledge". However, the problem is that there is absolutely no further explanation about what is meant by "protection" in this context and what the concrete legal measures and other means to achieve that objective would be. Under the cover of this so-called protection lies biopiracy as a stark reality that African countries and many other countries all over the world are facing. For example, there was a public outrage expressed to Council for Scientific and Industrial Research (CSIR) about the filing of a patent for active compounds of the Hoodia plant responsible for suppressing appetite.

The indigenous San had used the plant for centuries for this purpose, but the CSIR did not get consent to use this IK, and the San were not acknowledged 
in the patent application. International media coverage and NGO pressure forced the CSIR and the San to develop an agreement of mutual benefit. The CSIR bioprospecting agreement was then signed on the $28^{\text {th }}$ October 2004 in Upington (Horak, 2005). It is therefore important, in addition to laws and procedures, to develop informal processes to promote dialogue and build consensus between stakeholders.

2.2.2.2 Traditional medicine from medicinal plants perspective

A great majority of populations in sub-Saharan Africa rely on plants to ensure their primary health care as indicated in the preceding sections. Within the plant kingdom, medicinal plants form the largest single grouping of plants. It is estimated that 30,000 species worldwide fall in this group, of which around 33\% are trees (Shankar, 1998:400). A literature search conducted by Plant Resources of Tropical Africa (PROTA) has recorded 6, 377 plant species used in Tropical Africa, out of which 1,975 are primarily used as medicinal plants, and 2,074 have also medicinal applications although this is not their main use (Bosch et al., 2002).

Medicinal plants are used in various traditional systems of health in Africa as well as contemporary or alternative medicine in western societies. The terms contemporary medicine or alternative medicine are used inter-changeably with traditional medicine in some countries. Alternatives or contemporary refer to a broad set of health care practices that are not part of that country's own 
tradition and are not integrated into the dominant health care system (WHO, 2000:1-6).

\subsubsection{Traditional Medicine in South Africa}

For many years, many cultures all over the world have known the healing and spiritual qualities of plants. Many practitioners of western medicine have disregarded the work of African THPs and South Africa's traditional healing folklore as quackery. At the same time western medicine flourished while the role of traditional medicine gradually diminished. The use of medicinal plants is a thriving industry in South Africa. The use and treatment of ailments began to differ according to different practitioners and geographical location. According to Shackleton et al (2000) millions of rural South Africans depend upon biological resources for day-to-day survival. Access to the natural capital provides a crucial contribution to livelihoods, a buffer against poverty and an opportunity for self-employment. MRC (1997:1) estimates that up to $80 \%$ of the African people in South Africa use traditional medicines and Mander (1998) reports that there are more than 100000 practising THPs in the country, with a contingent industry worth about R500 million per annum.

It was indicated in chapter 1 that $70 \%$ of the South African population dependant on traditional medicines derived from indigenous plants and animals (SANBI, 2005:3). It was also mentioned that some people utilize traditional medicine as a second choice probably due to the stigmatization and marginalization of traditional health care in the country. Observations and 
discussions confirm many accounts of people who visit THPs late in the evening in order to eliminate the possibility of being seen are consulting THPs. It can't be disputed that the arrival of Christianity that accompanied colonisation, all over Africa contributed a lot in the marginalization of traditional medicine.

South Africa is blessed with a rich plant biodiversity of more than 24,000 indigenous plants, representing about $10 \%$ of all higher plants on earth (MRC, 1997). The MRC (1997:5) confirms the estimate of at least $70 \%$ of all South Africans that consult one of the more than 200,000 THPs in the country. Estimates of THPs in South Africa vary between 150, 000 and 350, 000, while the number of conventional doctors is around 25, 000 (Kale, 1995:11821185). It is important for the researchers to understand what traditional medicine is and where it originated.

Traditional medicine encompasses plants and animal products. According to Wynberg (2002:233) South Africa stands proud as the third most biologically diverse country in the world, containing between 250, 000 and 1, 000000 species, many of which are endemic (World Conservation Monitoring Centre, 1992). Although research into medicinal plants is aimed at the discovery of new commercial drugs, it should also be aimed directly at achieving conservation and sustainable use, especially through enhancing the abilities of THPs and communities to do so. 
As a result of the wide and unsustainable use, increasing economic importance, and environmental factors, medicinal plants resources are diminishing at an alarming rate. The loss of medicinal plants diversity is compounded by the even more rapid loss of indigenous knowledge on medicinal plants and traditional medicine in Africa, as a result of the death of the elderly people who are custodians of this knowledge, and the rapid sociocultural transformation of societies, limiting the transfer of knowledge to younger generations.

Plants may be overexploited as a result of economic policy and failures (Swanson, 1992:250-257), but physiological features will make some kinds of plants more vulnerable to overexploitation. Unemployment and poverty is forcing communities to generate income by selling or using traditional medicine. In South Africa, Cunningham (1991) has identified two causes of overexploitation of medicinal plants. Firstly, a dramatic decrease in the area of indigenous vegetation, due to the expansion of agriculture, afforestation and urban development is the major factor. Secondly, a rapid increase in the use of medicinal plants, and a corresponding increase in demand for traditional medicines contribute to this trend.

Commercial trade in South Africa predominates and this overexploitation has resulted in a rapid increase in the prices of species that have been depleted in the wild. Oldfield (1984) observed that those plants most vulnerable to extinction are those that are naturally rare and must be sacrificed to yield the desired products, yet are long lived, slow maturing, and difficult to cultivate or 
domesticate. The category identified as being of great concern to THPs by Cunningham (1991) is that of the slow-growing, popular species with a restricted distribution which are exploited for bark, root tubers, bulb/corms or where the whole plant is removed.

South African government has recognised the critical need to legal recognition of THPs and their indigenous knowledge about health and healing systems. South African leaders have taken a number of key initiatives to deal with the unique situation of traditional medicine. The National Drug Policy of Department of Health (1996) recognises the potential role and benefits of traditional medicines in the National Healing System. This policy is aimed at investigating the use of effective and safe traditional medicines at a primary level and further addresses:

- the investigation of traditional medicines for efficacy, safety, quality with the aim to incorporate their use in the national healthcare delivery system;

- registration and control of marketed traditional medicines; and

- provisions for the establishment of a National Reference Centre for African Traditional Medicines for the purposes of gathering harnessing and synthesizing information to promote, regulate and register African traditional medicines of plant origin. The policies have further enhanced by the Traditional Health Practitioners Act 2004 through which the Interim Traditional Health Practitioners Council of South Africa will be established. 
The South African government has greatly evolved in recognising THPs, their knowledge and healing ways, as integral partners in the formal healthcare system required to meet the extreme challenges of the $21^{\text {st }}$ century. South Africa has a rich heritage and much has to be offered to the world by documenting and protecting the indigenous knowledge systems and practices of THPs. The discovery of the healing properties of medicinal plants such as the African willow, wild ginger - serokolo (South Africa), and hoodia plant , devils' claw - sengaparile (South Africa and Namibia) and iboga (Gabon and Cameroon) emerged from the knowledge of THPs. In this study the exploration of THPs' knowledge about medicinal plants and the environment, make provision for the acknowledgement and respect due to them.

Within development circles there is a suspicion of technology as too often promoting expensive, inappropriate fixes that take no account of development realities. The vibrant sectors of African economies are at the informal sectors. The interesting issue here is that many of the agents and agencies associated with informal economy tap into the accumulated skills and expertise and IK from traditional Africa. According to Principle (1989) by one estimate, the market value of plant based medicines alone in developed countries amounted in 1985 to US\$ 43 billion. However, only a tiny proportion of this has ever been returned to the source communities. It is probably impossible to estimate the full market value of IK. The THPs has determined their own destinations by creating their own economies through traditional health systems. Aspects of economic and trade issues are subsequently discussed. 


\subsubsection{Economic and trade issues}

Medicinal plants contribute significantly to rural livelihoods of the people and social equilibrium in Africa. Apart from THPs who derives monetary and/or non-monetary benefits from traditional medicine practice, a lot of people are involved in collection and trade of medicinal plants. A decade ago, a WWF/UNESCO report noted that in Africa, which has the highest rate of urbanization in the world, the larger the urban settlement, the larger the traditional medicine markets tend to be. Increased pressure is thus placed on rural stocks through unsustainable harvesting practices to meet burgeoning demand. The report noted that "there is significant evidence to show that the supply of plants for traditional medicine is failing to satisfy demand" (Cunningham, 1991). The 2004 global market for herbal medicines including herbal products and raw materials is estimated to be US\$ 65 billion (based on a WHO, 2001 estimate of US \$45 billion with an annual growth rate of 5-15\%).

In South Africa, 400 to 550 species were said to be sold for use in traditional medicine, of which an estimated 99\% originate from wild sources (Williams, 1996:12-14). Williams et al (1996) has indicated in their report that the informal medicinal plant trade is estimated to total R21 million per annum in the Gauteng area alone and R60 million in KwaZulu Natal province (Mander, 1998:36). About 19, 500 tons of medicinal plants are traded each year in the country as a whole, with trade value of R270 million (Mander, 1998:36). Approximately 3, 000 species are used by an estimated 200, 000 THPs (Van Wyk et al., 1997:10). The demands of medicinal plants at local and 
international markets are continuously growing, as well as bio-prospecting activities searching for sources of new drugs. Mander (1997a:62) has reported that there were about 1,000 THPs in the Bushbuckridge Area (Mpumalanga Province) and between 2,000 to 3,000 income-earning opportunities associated with medicinal plants.

The demand for medicinal plants in this area was estimated at 200 tons per year, and the value of the medicinal plants used or traded was R17-26 million a year. Another survey by Mander (1997b) reveals that more than 4,000 tons of medicinal plants were traded per year in Kwazulu Natal province. The estimate was that 20,000 to 30,000 people were getting an income trading in medicinal plants. The demand exceeds supply, which is continuously declining. As WHO (2002) indicates: "The global market for traditional therapies stands at US\$ 60 billion a year and is steadily growing. Unmonitored trade of medicinal plant resources, destructive harvesting techniques, over-exploitation, habitat loss, and habitat change are the primary threats to medicinal plant resources in most developing countries (IUCN, 2001; IUCN, 2002). The figures above shows potential benefits and a formal market for medicinal plants should have been established in support of THPs and communities rather than outside agencies.

Based on the economic and trade issues in Africa and South Africa, it is apparent that the degree of disturbance to the species population and vulnerability to overexploitation depend on demand and supply. This study addressed the issue of extinction prone medicinal plants from the 
understanding that the THPs should take the centre stage in managing and conserving the medicinal plants and their environment for future generations and curing different serious ailments in the African continent. 


\section{CHAPTER 3}

\section{RESEARCH APPROACH}

\subsection{INTRODUCTION}

In this chapter, different approaches were used to gather information from THPs. Given the nature of the research, it was determined that a qualitative approach would provide the most effective tool for data collection. Interviews were considered the best method for data collection as they are effective in giving a human face to research problems. They are also effective in getting people to talk about their personal feelings, opinions and experiences. The methods used also provided descriptive review to be placed in the context of traditional beliefs creating an entry to the research approaches. Audio-visuals were used to record the interviews using an interview schedule. The interviews were captured on video tape with full verbal informed consent and the researcher was not distracted by taking notes. The respondents were all relaxed while being filmed and conversed uninhibited and naturally regardless of the camera.

\subsection{Study area}

The study areas fall within the Capricorn and Greater Sekhukhune district, two of five districts in the Limpopo Province of South Africa. The Capricorn District is named after the Tropic of Capricorn $\left(23 \frac{1}{2^{\circ}}\right.$ southern latitude) which runs 
through the district. The majority of its 1, 154673 people are Pedi (Statistics South Africa, 2001). Sepedi is the home language of $88 \%$ of the population in the district (Statistics South Africa, 2001). The Capricorn district share borders with Vhembe, Mopani, Greater Sekhukhune, and Waterberg districts (Figure 3.1). The Greater Sekhukhune district has a population of around 967, 126 people and the majority are Pedi (Statistics South Africa, 2001). According to Statistics South Africa (2001) Sepedi is the home language of $83.36 \%$ of the population in the District.

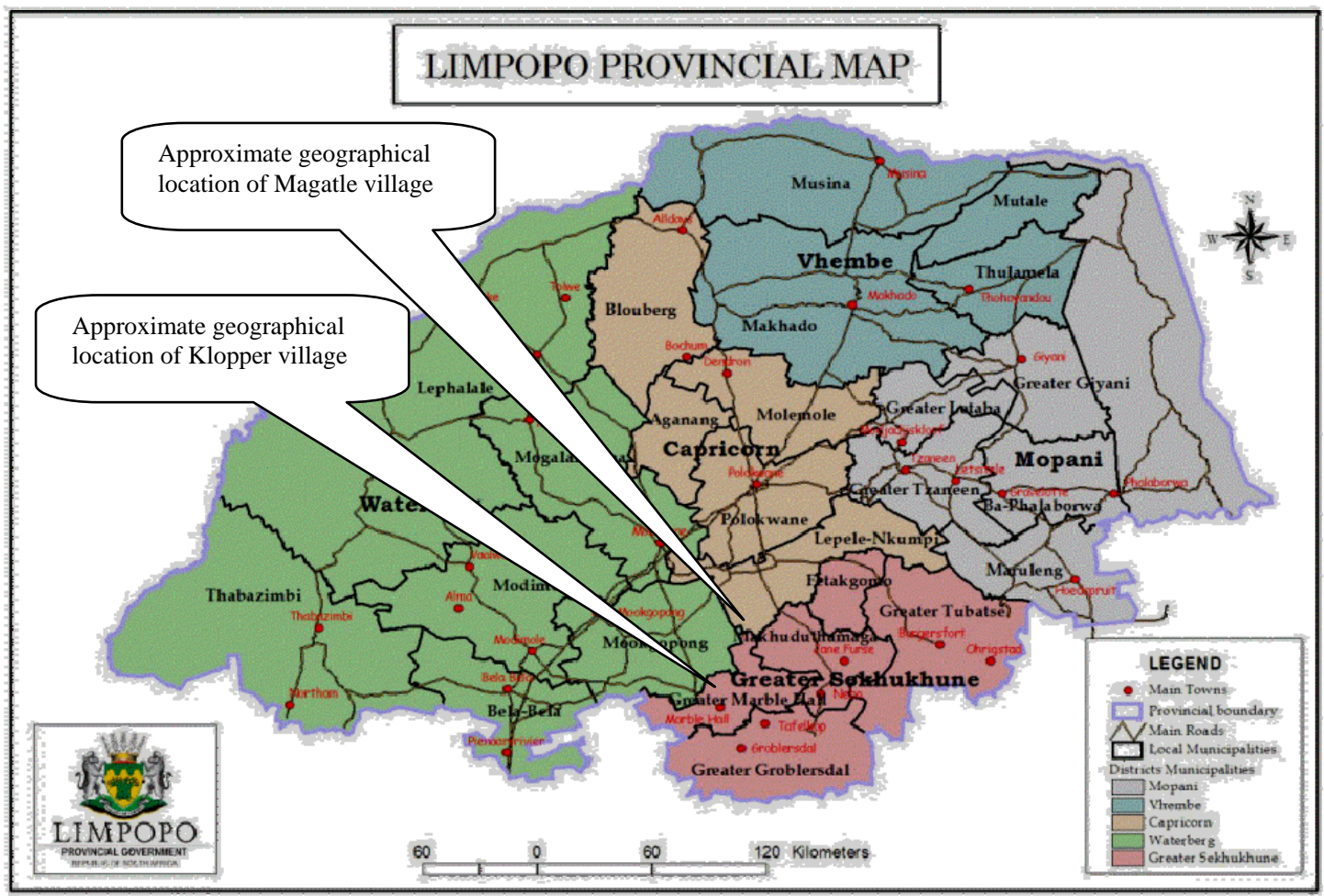

Figure 3.1: Map of Limpopo province and approximate geographical locations of study area (adapted from Marula Marketing, 2007)

The study was conducted at Magatle village in the Lepelle Nkumpi municipality and Klopper village located in the Marble Hall municipality. The 
villages are approximately 38 and $45 \mathrm{~km}$ North and South West respectively of Marble Hall.

\subsection{Initiation of the study}

The research approach undertaken for the study was based on two field work periods. The first period (Phase I) was conducted between June and July 2005 and the second period (Phase II) between January and March 2007 in the Greater Sekhukhune and Capricorn district, Limpopo Province. Because the districts are geographically located next to each other it was feasible to utilise the THPs in the two districts without considering the borders as they don't limit their movement during harvesting. These villages were selected primarily because of personal contacts that the researcher has that adhere to the criteria specified. The criteria specified has emanated from the workshop which was conducted at Magatle village from 22 to 23 June 2005 by the Agriculture Research Council (ARC). THPs from the two districts are in no way representative of the districts, but the overall aim of the workshop was to identify very scarce, important and easy to plant medicinal plants.

The selection of THPs for Phase II of the study were made after the completion of the Phase I workshop and were based on the following criteria:

- Attendance and active participation during the Phase I workshop in listing and naming medicinal plants. Their responses at the workshop 
raised questions and informed the interviewing schedule that was used during Phase II.

- Knowledge of medicinal plants as measured during the Phase I workshop making use of a list of possible medicinal plants that are available in the ecological area and selecting THPs that could name and identify most of the plants listed.

- Experience of at least 5 years of traditional healing with active involvement in medicinal plant use, clients and patients.

The outcomes of the workshop revealed that the THPs have serious problems with scarce medicinal plants and are concerned about some medicinal plants that are prone to extinction. It was however, acknowledged that healing practices differ from one person to another and these issues were investigated during the Phase II interviews.

\subsubsection{Phase I}

Phase I included the investigation of study locations during visits in 2005/6 to conduct a workshop for the purpose of encouraging THPs to protect and conserve plants of medicinal value and to protect the rights of THPs (Figure 3.2). The data gathered during the workshop was based on probing questions to identify the THPs perceptions towards the interaction between farmers, THPs and traditional hunters in developing strategies to protect and conserve natural resources by engaging each other, exchanging ideas, learning and influencing each other in developing their knowledge base. 


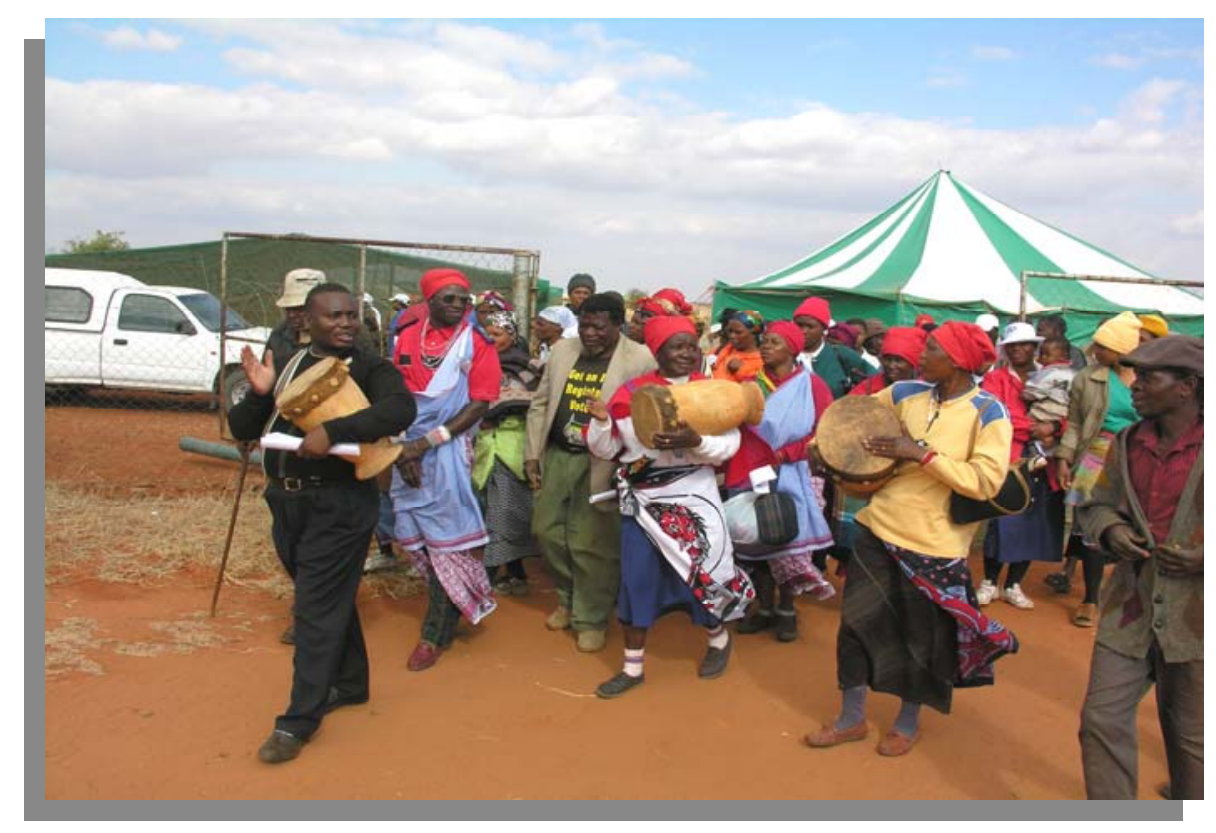

Figure 3.2: THPs' who attended the workshop at Magatle Village from $22^{\text {nd }}$ to $23^{\text {rd }}$ June 2005

Furthermore, several visits were undertaken to $\mathrm{Dr}$ Tsiane School of Traditional Healing in September 2005 and May 2006 before formalizing the research and commencement of the study. Eighty THPs attended the workshop and 156 medicinal plants were listed. The THPs' insights, coupled with botanical and ecological knowledge of the plant species involved, provided an essential source of information for the initiation of the study. The information of the THPs was recorded using a flipchart and names of medicinal plants written using their local language. The local names were verified with the THPs whether they are correctly spelt. The medicinal plants were also prioritised in terms of how easy or difficult they are to grow and how accessible they are. In the study, it was not considered constructive to distinguish between plant species with symbolic uses and those with active ingredients. The important question here was whether the THPs has 
problems, opportunities and challenges in acquiring medicinal plants in the study areas.

\subsubsection{Phase II}

For Phase II, visits were conducted at the identified study area as mentioned in paragraph 3.1. Prior to conducting the research, verbal informed consent representing cultural perspective and protecting the integrity of THPs and rights were obtained. Data was collected using participant observation, in depth interviews and unstructured interaction with the THPs who were selected after the completion of Phase I. The 20 THPs that were identified (10 women and 10 men) were interviewed. An interview schedule was used during the in-depth interviews (Appendix A). The interviews were recorded on video and audiotape, transcribed, and analyzed for commonly occurring concepts, ideas, and themes that provided insight into traditional medicinal plants. The interviews and discussions were conducted in Sepedi and translated to English.

Triangulation was used to assess the same data and the interpretation of the data was cross-checked with the THPs to clarify terms and concepts. The THPs were interviewed at a place most comfortable to them. The interviews were conducted during koša (traditional dancing of THPs). Information regarding the problems, constraints and challenges in harvesting traditional medicinal plants, extinct prone medicinal plants and causes of habitat loss in the study areas was collected. Additional discussions were conducted with the 
THPs in order to understand the traditional health system. Specimens of the plants mentioned were identified from their natural habitat and agro-ecological environments. This was done in order to recognise the environment where they grow and be able to identify them as reported in chapter 4 .

During the course of the study, each THP was interviewed twice in order to verify the reliability of data obtained. If what was said during the first interview concerning the use of a particular medicinal plant by a THP which did not agree with what was said during the second interview concerning the problems, constraints and challenges in harvesting and list of extinct-prone medicinal plants, the information was considered unreliable and was rejected. Repeated visits and observations also helped to gather additional information that was not mentioned during earlier interviews. The relative popularity of each medicinal plant species was evaluated on the proportion of THPs who independently reported its scarcity.

Within every member of any group there is a lifetime of experiences and knowledge and literature refer to these groups as communities of practice (Wenger, 1998). It was therefore important to tap the collective knowledge of the THPs to craft the best decision possible about diverse practice of medicinal plants. The THPs were also asked to list at least three very scarce medicinal plants in their areas emanating from the information reported during interviews and observations. The causes of habitat loss of the listed medicinal plants were also recorded. It was also important for the THPs to make their contributions by stating what needs to be done to ensure effective 
conservation of all medicinal plant species. Their views were recorded using a video camera yet there were no limitations in using the equipment as each THP was interviewed separately from others who might influence the interactive process. The time that was spent with one THP depended entirely on the responses of the participant. 


\section{CHAPTER 4: RESULTS AND DISCUSSIONS}

\subsection{INTRODUCTION}

This chapter report on the outcomes of the research conducted. The findings of the study covered areas such as THPs' practices, problems, opportunities and challenges, scarce medicinal plants, causes behind the depletion of medicinal plants and possible solutions suggested by THPs. This study contributes to filling the observed gap of engaging THPs by researchers regarding their practices and sustainability of harvesting medicinal plants that can best serve to advance its integration to the conservation strategies of the country. The past, present and potential contributions of IK were noted. The research questions raised in chapter 1 were considered in the light of the findings of this study.

\subsection{Documentation of scarce medicinal plants}

During an annual festival of THPs in 2006 (Figure 4.1) a total of 20 THPs that operate, work or consult within the boundaries of the study area that has been identified in paragraph 3 were interviewed. Information gathered from the THPs revealed that THPs are unable to find medicinal plants within their surroundings and many traditional medicinal plants are under threat of overexploitation and extinction where they used to be found. Twenty four medicinal plants species were mentioned by the THPs to be important to their practices. 


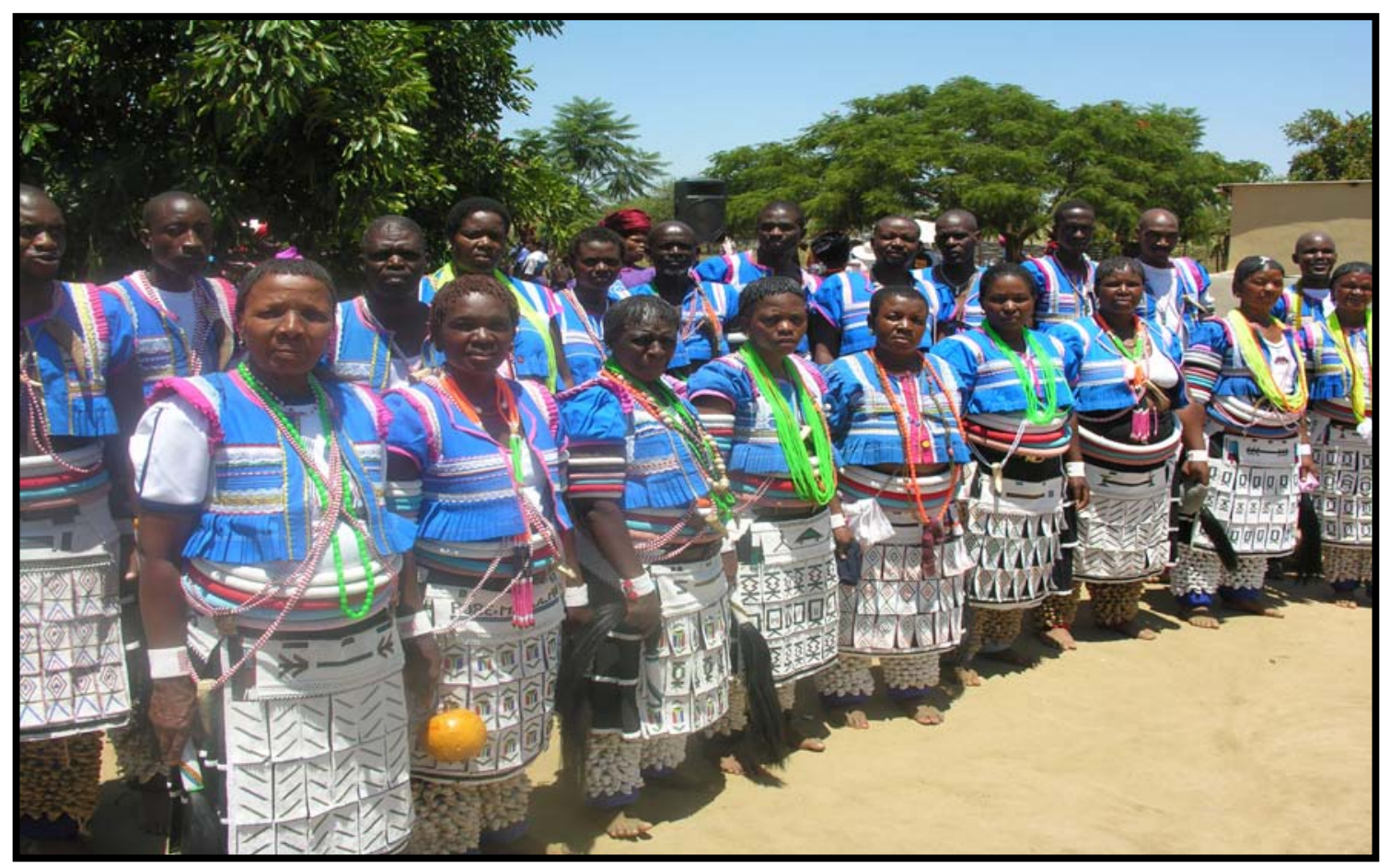

FIGURE 4.1 Some of THPs concerned about scarce medicinal plants

Table 4.1 shows medicinal plants that were identified by THPs as well as the parts of each plant that is used for healing purpose. During the interviews it became evident that the THPs recognize the need to harvest medicinal plants sustainably from the wild and develop strategies and actions to reduce the impacts of harvesting. The local knowledge about plants as explored in chapter 2 in this research is acknowledged and can be better understood if it is recognized that it is based on a distinctive epistemology which is unique to the THPs' culture. Most of the listed medicinal plants are geographically located very far from the research areas and the wish was expressed by THPs to acquire most of these medicinal plants because they don't have transport and where transport is available it is costly. 
TABLE 4.1: List of medicinal plants in terms of scarcity

\begin{tabular}{|c|c|c|}
\hline Name & Scientific/family Name & Part harvested \\
\hline 1. Fera & Santalaceae $e^{\star \star \star}$ & roots \\
\hline 2. Rooistrong/madi a phalane & Hyacinthaceae $e^{\star \star \star}$ & roots \\
\hline 3. Pharagobe & Anacardiaceae ${ }^{\star \star \star}$ & roots and leaves \\
\hline 4. Lehlwele & Gunneraceae & roots \\
\hline 5. Moraroana & Asclepiadaceae $e^{\star \star \star}$ & stem \\
\hline 6. Hlonya & Rubiaceae ${ }^{\star \star \star}$ & roots \\
\hline 7. Batswetši & Elephantorriza Elephantina* & roots \\
\hline 8. Mokapoomogolo & Cussonia paniculata** $^{\star \star}$ & roots and twigs \\
\hline 9. Hlokwalatsela & Dipsacaceae* & roots \\
\hline 10. Maroke & Verbenaceae* & leaves and twigs \\
\hline 11. Morothamadi & Anacardiaceae* & roots and bark \\
\hline 12. Mohlaba-batsumi & Rhamnaceae ${ }^{\star \star \star}$ & leaves and twigs \\
\hline 13. Molaka & Warbugia salutaris* & leaves \\
\hline 14. Mphahlašilo & Flacourtiaceae ${ }^{\star \star \star}$ & roots \\
\hline 15. Thitidi & Hypoxis Hemerocallidea* & rootstock (corm) \\
\hline 16. Bjere/mokwalo & Asclepiadaceae & roots and stem \\
\hline 17. Leshogwane & Asteraceae* & roots \\
\hline 18. Segwete & Scabiosa Columbania*** & roots \\
\hline 19. Tshukane & Hyacinthaceae ${ }^{\star \star \star}$ & roots \\
\hline 20. Bore bja Tau & Grassulaceae & leaves and roots \\
\hline 21. Makgolwa & Apocynaceae* & roots \\
\hline 22. Matlapaneng & Myrothamnus flabeuifolius* & leaves and twigs \\
\hline 23. Leakalala & Hyacinthaceae ${ }^{\star \star \star}$ & roots \\
\hline 24. Senamane & Eucephalartos woodii** & stem \\
\hline
\end{tabular}

* Van Wyk et al, 2002.

** Plants of Southern Africa, 2005

$\star \star \star$ Thomas et al, 2002 Species identified up to family name

The first four names listed in bold face indicate great importance and higher susceptibility to being extinction-prone. Medicinal plants are inherently extinction prone due to the roots being harvested. Prolific practices of continuous land-clearance because of developmental pressures along with indiscriminate veld fires, wood collection, deforestation as well as drought. During harvesting, plants are uprooted as observed in the veld. The THPs have indicated that the uprooting of a plant is actually the work of collectors of medicinal plants who are interested in income generation activities. It was 
observed that THPs do not uproot plants but the soil covering the roots is gently removed to reveal their root structure and setup. Thereafter, only side roots are removed leaving the taproot untouched and allowing the plant to regenerate. In some instances, the roots are harvested during flowering and rainy season. This has negative impact on the plant as the process doesn't allow quick re-growth and become unsustainably utilised.

As shown on the table 4.1, 24 medicinal plants were listed, each THP was asked to list at least three medicinal plants most important to her/him. It was however indicated that the first four medicinal plants indicated in Table 4.1 are very important to THPs practices and also extinction-prone in the research areas. However, THPs provided more information concerning problems, constraints and challenges in harvesting and medicinal plants in the second interviews during which the unreliable information was rejected. The triangulation method that was used, as discussed in chapter 3 provided an indication of unreliable information. Terms and concepts were clarified during second interviews and this is indicative of the diversity of THPs practices and the wide range of medicinal plants in use among them. The listed medicinal plants are harvested at different locations and are found in clay, red loam soils and rocky areas (see figure 4.1., 4.2 and 4.3) These are:

- Rooistrong/ madi a phalane (runner/climbing) - it is found next to streams around Mooka (Acacia karroo) tree in shallow soils. 
- $\quad$ Fera (tree) - it is found around mountains and hills in rocky areas

- $\quad$ Lehlwele (woody underground rootstock) - it is found next to streams in cracked clay soils and it is distributed in the grassland areas.

- Pharagobe (tree) - it is found around mountains and hills in rocky areas.

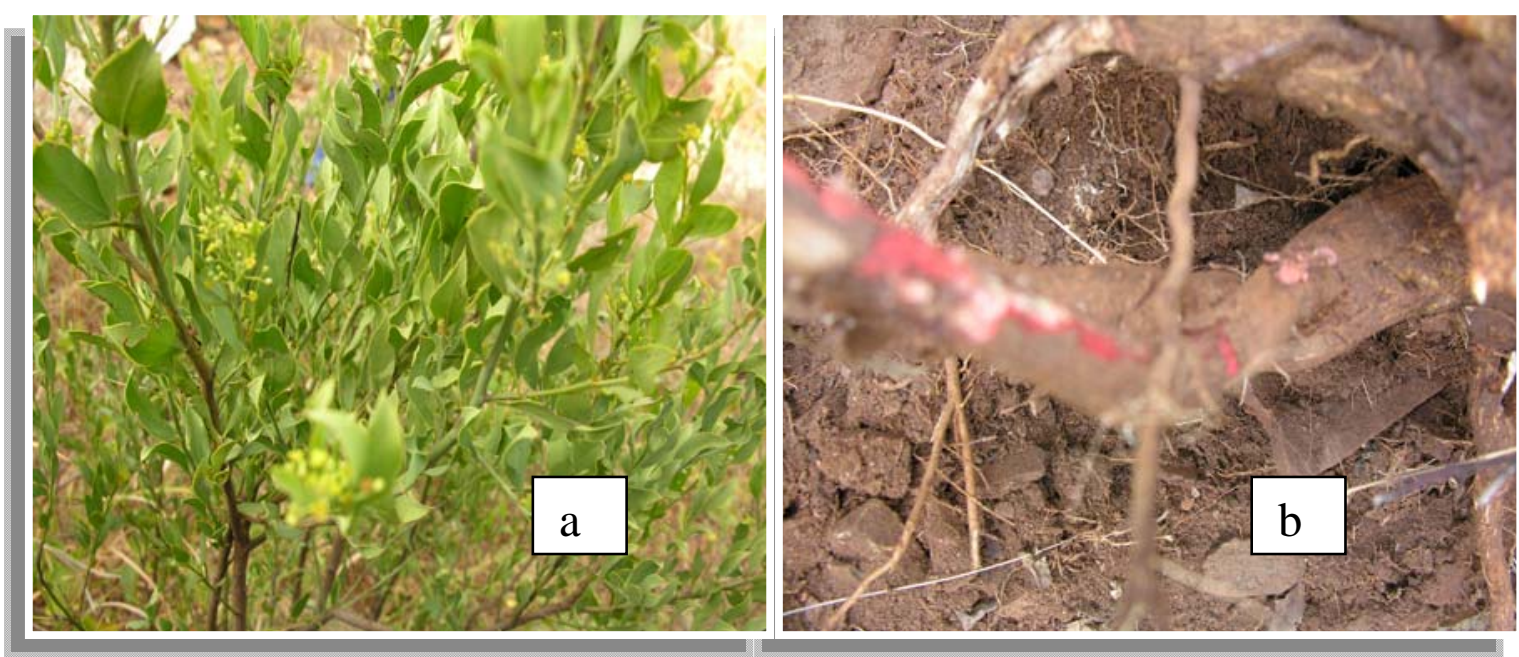

Figure 4.1: Fera plant (a) and roots (b)
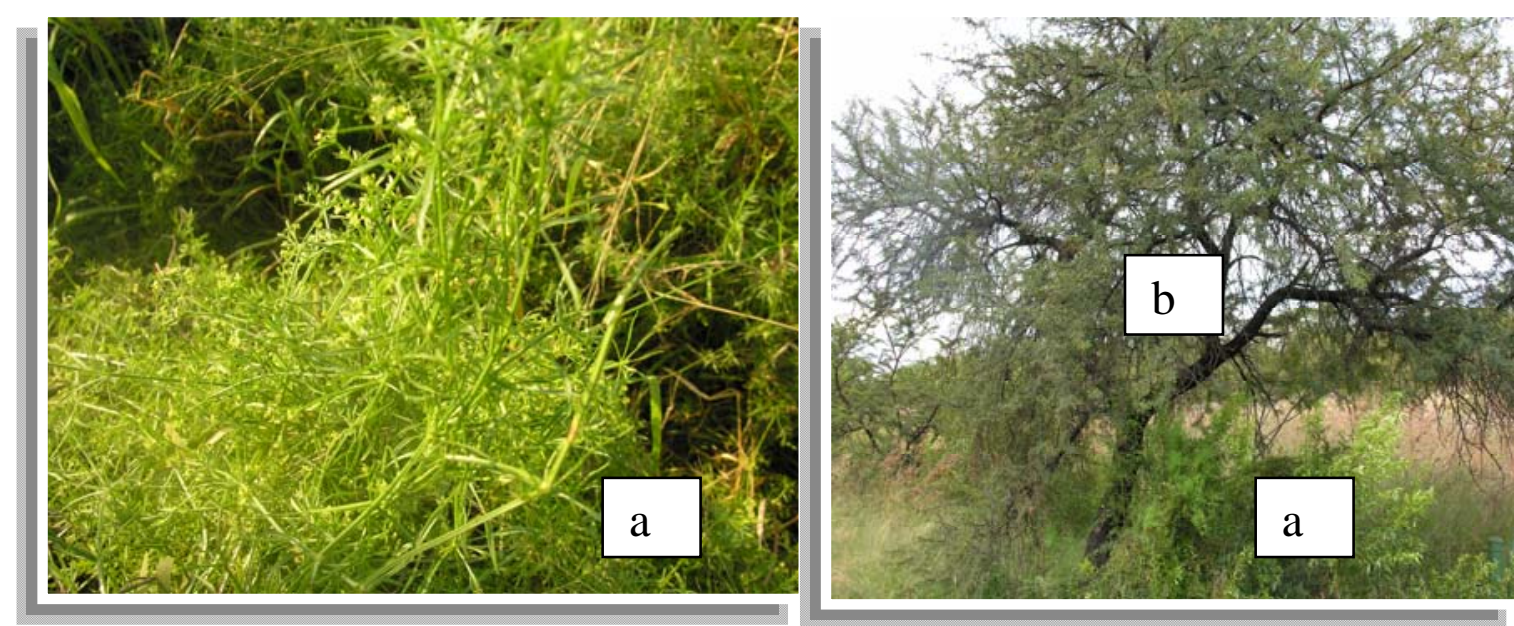

Figure 4.2: Madi a phalane plant (a) and mooka tree (b) 


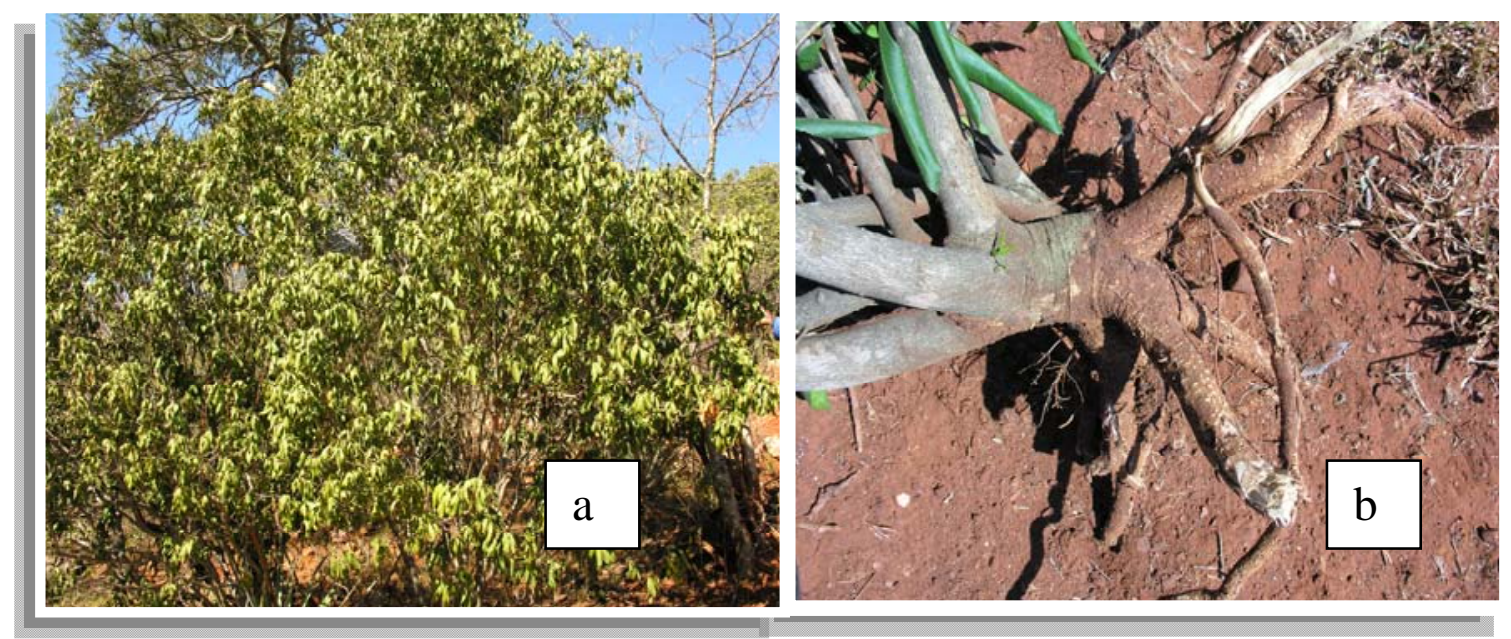

Figure 4.3: Pharagobe plant (a) and roots (b)

\subsection{Harvesting practices}

Of the 24 plants listed in Table 4.1 to be mostly utilised by THPs different parts of the plants are used, ranging from roots, bark and leaves. All THPs have indicated that the roots of the plants work better because it is believed that this is the portion of the plant where the healing power rests. Even though the roots were indicated as better than other parts of the plants, some THPS rather use leaves, bark and the roots of particular species are used in varying levels.

When THPs were asked about who is regarded to be depleting medicinal plants, the response was that the damage to the environment is done by (outsiders/traders). The verbatim response: Batšwakantle-batho bao ba sa dulego mo motseng goba barekiši ba dihlare. This mean outside people who are nor staying in the village or traders selling plants. The THPs also regard themselves as well as community members who mostly collect plants indiscriminately for fuel wood contributing to the depletion of medicinal plants and it was elaborated that the THPs who are desperate for medicinal plants 
has been found to be destructive to the environment. This is due to an alarming rate of illnesses occurring in the country and a growing number of patients requiring traditional treatments.

During interviews with the THPs, it was clear that outsiders and community members collect medicinal plants for income generation and these pose a great threat to the natural habitat. It was revealed that the collectors are ignorant about proper time of collection as well as season. The collection of medicinal plants by THPs is done during summer because the plants are visible and identifiable and once identified are collected in large quantities. This would also give the remaining plants an opportunity to recuperate during the growing season, which will not be the case if collection was done in winter.

It was observed during harvesting that the roots are dug-out and the soil is not refilled again. The reason given by THPs is that this will result in worsening the sickness of the patient if the soil is refilled. It was indicated that the pit will close up as the time progresses during the rainy season. This practice does not seem to threaten the surrounding plants as few side roots are collected and the root system is not exposed. However where the plant being harvested is completely uprooted, the surrounding plants seemed to be affected in terms of exposing parts or complete root systems of the surrounding plants. It also depend on the kind of plant harvested, whether soft or hard wood. When collecting roots, not all roots are removed from the tree, but most are left so that the tree can continue to grow (Mavi \& Shava, 1997). Mckenzie et al (1996) reiterates that removal of roots has little effect on a future population 
structure of the species. Harvesting of medicinal plants by THPs involves diila and rituals. According to Mayeng (1996) and Mavi (1996), such diila normally are used as measures to ensure the conservation of medicinal plants and the protection of the ecology in general. The norms and procedures were observed and reported not always to be adhered to. The reason for this is the collection and commercialisation of items by people who are not THPs, and who lack knowledge of the rituals used by THPs. According to Mavi (1996), failure to follow the rituals will render the medicinal plants collected ineffective. During interviews the THPs reported that they hold the same sentiments expressed by Mavi (1996) regarding the effectiveness of the harvested medicines.

While busy harvesting bark from a tree the question was asked whether the THPs will continue harvesting the specific plant as it was already been damaged. The THPs indicated that harvesting will not continue from that plant as the associated diila with regard to this practice doesn't allow continuous harvesting as the THPs are not sure whether a disease has been transferred to the plant. The belief is shared by all the THPs interviewed.

Through observation, all plants being harvested were harvested on the eastern side of the plant and the associated diila given was that the medicine would be rendered impotent if harvested on any other side. According to THPs, the tree is getting enough sunlight on the eastern side and the sun is said to play an important role in the tree's healing process. Scientifically, this method allows the tree to recover from wounding (Van Staden, 1998; Kambizi 2000). Further scientific explanation of the indigenous knowledge practice 
regarding harvesting of bark ensures that trees are not ring-barked through continuous harvesting from the same tree and correct harvesting of bark would therefore not threaten the survival of the plant. It seemed that uncontrolled bark harvesting of the trees led to extinct of the trees and this approach or traditional method prevented this (figure 4.4)

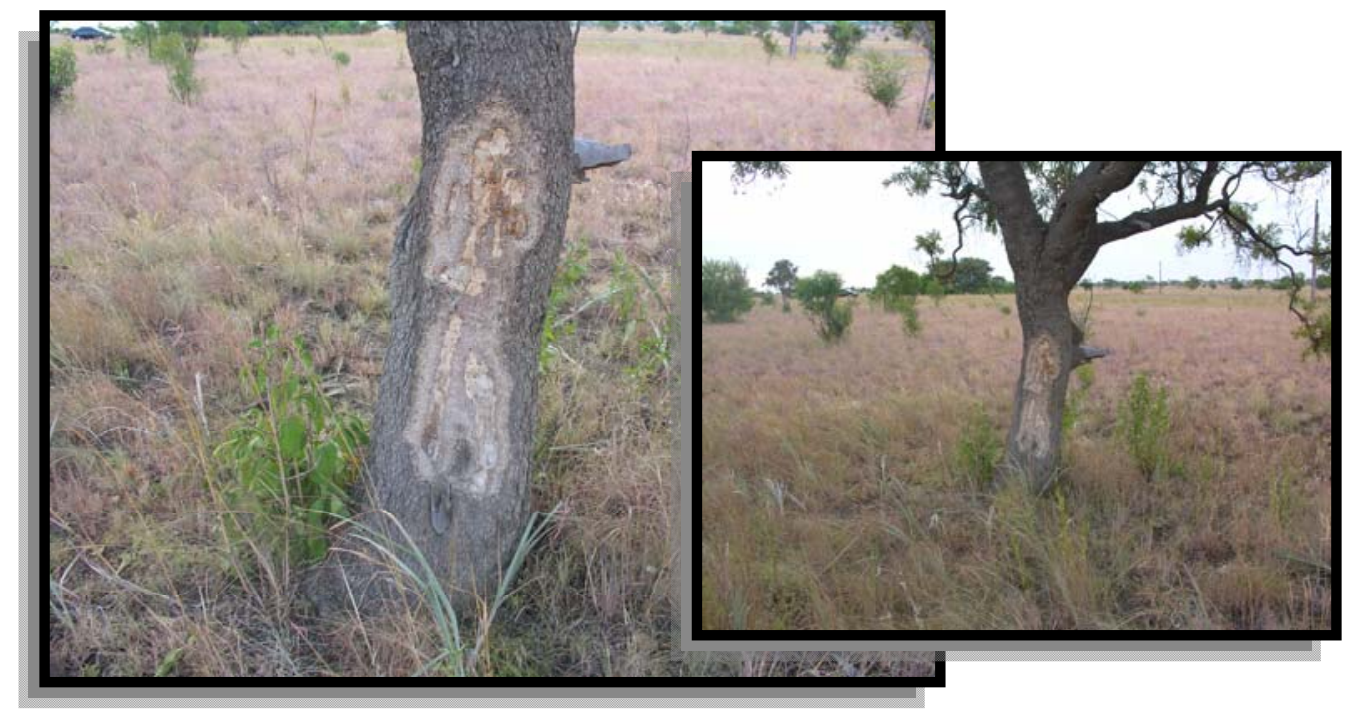

FIGURE 4.4: A tree showing signs of bark harvested on the eastern side of the tree

\subsection{The depletion of medicinal plants observed}

The environmental factors such as land degradation through erosion and/or development seem to be a leading loss of natural habitats. Population growth and increasing resource consumption has been indicated as one of the root causes of biodiversity loss as it create pressure to convert natural habitat into agricultural and industrial land. It was observed in the study area that the land set aside for residential purposes are extremely polluted with plastics, tins, papers and bottles which have a negative impact on quality of life. It is also obvious that many areas surrounding the villages bear evidence of disturbed 
natural plant growth and cannot be deemed as natural undisturbed areas any longer. THPs also reported that the manner which plants are collected is not keeping with tradition and is done by inexperienced people whose motives are based solely on supplying daily economic needs. There is therefore widespread concern among the THPs for the unchecked destruction in the natural environment often associated with development on which they depend for their vocational resource-base.

Furthermore, the THPs have listed problems, opportunities and challenges of harvesting medicinal plants from the wild.

\subsection{Problems:}

The problems identified by THPs during the interviews are listed as follows:

- Establishment of nature reserves - the THPs has concerns that the nature reserves established next to their areas (Marble Hall, Arabie, Roedtan, and Mdala Nature Reserve) prevented them access to the land previously owned by their forefathers. Abundance of medicinal plants in the reserves was accessible to communities prior to the apartheid government of South Africa. The access to nature reserves therefore, affects the choices available to THPs in sustaining their practices. Although identified as a problem, nature reserves, keep those indiscriminate harvesters out as well and this issue can be a solution if managed access can be given to THPS to harvest medicinal plants sustainability from the nature reserves. It is in 
the interest of both nature reserves and THPs to work together toward sustainable utilisation of natural resources.

- Harvesters not trained as THPs - the concerns raised by THPs relates to harvesters who debark and uproot medicinal plants for trading and therefore collection permits should be issued while the recognition by the South African government regarding THPs integration of their practices in the health system should be implemented. This will help facilitate protocols on conservation and sustainable utilization of medicinal plants. The establishment of THPs council will also help in implementing issues on indigenous products as stipulated in the National Environmental Management Act of 2004.

- Transport - this has been a major concern as most of the important medicinal plants are collected far away from where the THPs reside. This is also affecting THPs negatively as the costs of transportation rise occasionally meaning that their services will be more expensive and will affect the rural masses.

- Increased number of THPs - this has a negative impact on the environment because the demand for medicinal plants is also increasing and therefore threatens the available scarce medicinal plants.

- Harvesters who sell medicinal plants - as the number of THPs increases, the harvesters had to increase their supply and this also impact negatively on the environment and available plant species.

- Collection of medicinal plants for fuel-wood - it was however indicated that children and middle aged adults are not conforming to the cultural norms or customary laws because they collect plants indiscriminately for fuel 
wood and destroy important medicinal plant resources in the process. In the past, according to traditional custom, children were not allowed to bring any plants to the village from the wild and they were also taught which tree to cut for fuel wood. The impact that the loss of IK, traditional values and customs amongst the youth and other individuals have on the natural resource base on which communities depend is obvious through this example.

- Clearing of land for development purposes - most medicinal plants are removed during this process and forces THPs to travel long distances for other sources of medicinal plants.

\subsection{Opportunities:}

THPs identified the following opportunities based on the data collected during the interviews:

- Acquire land for production or cultivation purposes - the THPs are much willing to acquire land for the production of medicinal plants. The issue of restitution of ancestral land in South Africa is currently a source of confrontation between the state and various groups or communities who were dispossessed by union and apartheid governments of South Africa. Tenure arrangement in this regard is important. This will imply different degrees of access to and management of environmental resources by communities.

- Participate in government programmes on biodiversity - the THPs are encouraged by South African government in trying to respond to their 
needs by making contributions to the drafting of Traditional Health Practitioners' Act of 2004. They want to engage themselves in health and environmental activities of the government so that they respond to government legislations on biodiversity, IKS and environment, etc.

- Cultivate medicinal plants - propagation and cultivation activities are seen by THPs as something that might help avert the situation of scarce medicinal plants. There was an expression about this issue during the workshop. Three THPs out of the 80 attendees do not favour cultivation of the plants because the belief exist that healing power can be affected negatively in cultivated rather than wild specimens. A scientific study partly supports this. Uniyal et al (2000) made an observation that cultivated plants are sometimes qualitatively inferior when compared to wild gathered species. However, the cultivation of medicinal plants can reduce the extent to which wild populations are harvested. THPs interviewed believe that cultivation would appear to be an important strategy for meeting a growing demand of medicinal plants and increasing number of THPs. According to Dold and Cocks (2001), 82\% of THPs interviewed in the Eastern Cape Province of South Africa stated that they would readily make use of cultivated plants because they recognize that wild supplies are declining.

- Register as THP with THPs Council to be established by South African government - the THPs feels that they should also be recognized as health practitioners and contribute to the health systems of the country. 


\subsection{Challenges:}

In addition to the stated problems and opportunities, the following challenges were furthermore identified:

- Full recognition of THPs by government - since the acceptance of the THP Act of 2004, there seems to be many challenges for THPs in terms of registrations, recognition and practices.

- Establish THP Council - the THPs has indicated that once the council is established, they will be able to create organized structures such as THPs branches etc.

- Register all THPs as practitioners in the health system of the country - the South African government seems to be delaying the implementation process which will ultimately strengthen the THPs structures.

- Have access to nature or game reserves - the THPs want to have managed access to the nature reserves in order to collect medicinal plants available. This will require different stakeholders to engage in discussions to allow THPs to collect medicinal plants from the reserves for propagation purposes and sustainable utilization.

- Fast-track the land reform programme - the THPs want to own land where they will be able to propagate and grow their own medicinal plants. The land reform programmes in this regard support the production of exotic plants in the form of agricultural produce rather than indigenous medicinal plants. The communities should be given the opportunities once the land is acquired to produce dual crops such as bambara groundnuts, pigeon peas, cleome etc for food and medicinal use. 
- Institutional support - the THPs requires that other stakeholders should support them in their bid to acquire land, register as THPs, establish THP council etc.

It is important when considering the above in terms of over-exploitation, scarcity, extinction-prone medicinal plants that communities should be proud of their heritage and determine how people in the pre-industrial era practised medicinal plant conservation. It is also important to educate people about their heritage to dispel unfounded myth that THPs destroy nature. As observed, loss of species and ecosystems has accelerated considerably in the last and current century. Industrial revolution has caused damage to biodiversity despite deliberations by THPs from socio-political perspectives.

Damage is evident through results of population growth, huge growth in food consumption and other factors like manipulated river systems where water flow has been dammed and local communities are restricted or robbed of natural water supply. Basically, the face of the earth has been changed drastically by high standards of living that involve high consumption of food and products and associated creation of more waste. In spite of the consumption, the establishment of formal and informal settlements alter the landscape and therefore affect the livelihood of traditional communities. It has already been stressed that THPs ecological knowledge cannot be separated from its social and cultural context. The fullest future development in the conservation of medicinal plant requires the maintenance of the cultural distinctiveness of indigenous communities. 


\section{CHAPTER 5: CONCLUSIONS AND RECOMMENDATIONS}

\subsection{INTRODUCTION}

This study was prompted by the need to document THP practices, record extinction-prone medicinal plants for sustainability and to determine the extent of THPs practices with the associated problems, opportunities and challenges with regard to harvesting of medicinal plants. From the results of this study, several conclusions and recommendations can be made.

\subsection{Conclusion}

In this exploratory study, it was observed that the knowledge of medicinal plants has been disseminated through family tradition as described by other researchers (chapter 2). From the results and discussions in chapter 4, it has been indicated that the renewed interest in IK will impact on South African educational and research institutions because THPs are willing to participate in activities that concern them. In the whole study knowledge of THPs has emerged and measured during the phase 1 workshop making use of a list of possible medicinal plants that are known, identifiable and available in the ecological area which became the framework within which that knowledge becomes meaningful.

The traditional customs and beliefs associated with the use and taboos of plants and animals placed temporary or permanent restrictions on their potential utilisation. In communities, informal systems of religious and spiritual taboos, the local customs, and the fear of community sanctions prevailed and supported conservation ethics and were sufficient to regulate people's 
resource use. The study revealed some challenges faced by THPs regarding their practices and harvesting practices that require special attention.

Solutions to the problems of exploitation/over harvesting of medicinal plants require local innovations and full participation of local communities in resource management initiatives. More importantly the IK should be remembered, identified, conserved and reinforced as a means to contribute to sustainable management of local natural resources with active participation of all local inhabitants. According to the local social norms of the THPs/communities that were researched the belief exists that plants act as homes to various spirits and destroying these plants represents chasing away spirits that are important in society's social and cultural beliefs. However the need to have sufficient supply for fuel wood for instance to cook the next meal could become more overwhelming in the mind of resource poor individuals than ill-supported traditional customs geared towards the protection of natural resources. The challenges of development are complex and need complex approaches to contain them.

It is also noted that certain development activities cause lasting damage to the rural landscapes. The problems and challenges raised by THPs require the policy makers to act in accordance to the democratic process. The THPs and communities used culturally relevant mechanisms to prevent excessive resource use and they used their own local capacities to make rational socioeconomic decisions and this should be encouraged. In earlier times, excessive resource use was minimal because the THPs and their families and apprentices collected and stored medicinal plants in accordance with 
traditions and diila which prevented over-exploitation. The local protocols in natural resource management entailed good practice for example: naming plants (male and female), diila, and discouraging children from collecting plants from the wild, collecting certain medicinal plants in winter or summer, condemning burning of veld and discouraging the harvesting of unripe wild fruits. It is therefore important to make recommendations that are to address local initiatives.

\subsection{Recommendations}

The recommended research and development options to address the problems, constraints and challenges of the THPs are:

- Coordinated efforts by stakeholders are needed for conservation, documentation and sustainable use of medicinal plants. The involvement of THPs and the community in any conservation effort is highly valued as without local community participation and mobilization, conservation efforts cannot be effectively materialized. The value of the plants needs to be recognised by all land and resource users.

- The collection of medicinal plants from the wild will continue to prevail owing to current state of affairs such as unemployment, diseases, poverty, escalating food prices, etc. Medicinal plant nurseries should be established and supported by government and local municipalities.

- Propagation and cultivation of extinction-prone medicinal plants should be encouraged by THPs throughout the country. Funding programmes for THPs should be a priority to facilitate the propagation and cultivation of medicinal plants. 
- Research to investigate the sustainability of production systems is lacking in South Africa and needs to be stimulated for a better understanding of the biological dynamics of the resource in the wild and in domestication. Recovery plans should be encouraged for all scarce and extinction-prone species to ensure survival of each species.

- Government policies and legislation need to be adapted and implemented to support THPs and recognize the value of and need for sustainable wild harvesting management regimes, to implement national and/or regional permit systems and make medicinal plant conservation a priority for national health and economic policy.

- THPs and communities can take greater responsibility for sustainable harvesting of medicinal plants only if they have the choices afforded by adequate income, control over resource and knowledge and skills required.

- THPs should have managed access to protected areas. The different tenure regimes will have varying implications for local people and THPs and some implications have been identified as follows:

- Purchase of land previously owned by the communities by private people/institutions may impact the THPs negatively because they have limited resources to buy medicinal plants from private land.

- Customary regimes may offer the necessary feeling of security about the future, provided the customary rules are respected generally in the communities, members of the communities with strong ties to medicinal plants are adequately included, and there is protection from exploitation by outsiders. 
- Land which has statutory protection has the potential to offer security of benefits to THPs, provided that the THPs are properly included in agreements on rights and responsibilities relating to the protected areas.

- Policies that give a community control over their knowledge should be developed and promoted. The current policies on indigenous knowledge systems, biodiversity, intellectual property rights should be promoted to communities through the establishment of community centres.

- Collectors of medicinal plants should be issued with collection permits that will encourage sustainable harvesting of medicinal plants and should also be encouraged to cultivate the plants.

\subsection{The challenges ahead:}

- One of the major challenges in planning for the sustainable utilisation and management of natural resources is to take into account cultural and ecological considerations. These vary from community to community within one culture and furthermore between various cultures. Any formalised management system should take cognisance thereof.

- Awareness of the relationship between a healthy environment and the well being of all communities needs to be enhanced. This challenge can be met by increasing effective communication among all parties concerned with the environment. In this context the communities, in particular the THP that are directly associated with 
the protected areas and IK, should become aware that they are the rightful owners and custodians of their IK and biodiversity.

- THPs should register with the THPs' council to be established by the government and thereafter develop their own research ethics that will guide their research endeavours in the area of medicinal plants and traditional health practices.

- Restoring the roles of traditional conservation methods, and $\mathrm{IK}$ in natural resource management. The issue is not "back-to-tradition" or naïve grassroots approach, but recognising, safeguarding and mobilizing local resources and knowledge in the development process.

Above all these considerations, it is clear that the propagation and cultivation of medicinal plants might help THPs sustain their practice and environment. It is also apparent that other stakeholders such as department of health, forestry, agriculture, environment and culture should embrace and be involved in initiatives from THPs. This will assist the government to conserve the natural resources and promote a healthy and clean environment. In conclusion, the study revealed that different approaches may be considered in the two districts to encourage sustainable harvesting of medicinal plants. Therefore, in-depth research on each specific species and the harvesting techniques and conservation approaches by THPs should be conducted. Scarce and extinct-prone medicinal plants should be propagated, conserved and sustained for future generations. In practical terms, conservation initiatives within communities will succeed if they are consistent with the local 
perceptions and the safeguarding and improving of the local lifestyles and with the need for local control over decision making process.

Further research is still required in:

- Addressing the conservation and sustainable use of medicinal plant genetic resources in terms of their geographic distribution and ecological requirements.

- The recording of known local uses of wild species and production of documents on medicinal plant conservation and sustainable use that would support local agendas.

- Investigations should be conducted on the sustainability of production systems amongst other soil requirements, propagation methods, irrigation requirements and post harvest handling. 


\section{REFERENCES:}

AIELLO, L \& COLLARD, M. 2001. "Our newest oldest ancestor? Sceptical look at the Orrorin tugenensis". Nature, 410:526-7.

BALTER, M \& GIBBONS, A (2000. A glimpse of humans' first journey out of Africa. Science, 2888:948-50.

BANNERMAN, R.H., BURTON, J. \& WEN-CHIEH, C. 1983. Traditional Medicine and Health care coverage. World Health Organisation, Geneva.

BATTISTE, M \& HENDERSON, J.Y. 2000. Protecting Indigenous Knowledge and Heritage: A Global Challenge. Saskatoon, Saskatchewan: Purich Publishing Ltd.

BOSCH, C.H., SIEMONSMA, J.S., LEMMENS, R.H.M.J. \& OYEN, L.P.A. 2002. Plant Resources of Tropical Africa (PROTA) programme, Wageningen, the Netherlands.

BOTHA, E.T. WITKOWSKI, F. \& SHACKLETON, C. M. 2003. Market profiles and trade in medicinal plants in the Lowveld, South Africa. Restoration and Conservation Biology Research Group, School of Animal, Plant and Environmental Sciences, University of the Witwatersrand, Johannesburg, South Africa \& Environmental Science Programme, Rhodes University, Grahamstown, South Africa. 
BUTLER, L. \& WAUD, 1990. Strengthening Extension Through the Concepts of Farming Systems Research and Extension (FSR/E) and Sustainability. Journal of Farming Systems Research-Extension 1(1): 77-98.

CHAMBERS, R. 1979. Rural Development: Whose Knowledge count? IDS Bulletin 10 (1979)2. Brighton: Institute of Development Studies.

CLARKE, R.J \& TOBIAS, P.V. 1995. Sterkfontein member 2 foot bones of the oldest South African hominid. South African Journal of Science, 269:521-4

CLARKE, R.J. 1999. Discovery of the complete arm and hand of the 3.3 million-year-old Australopithecus skeleton from Sterkfontein. South African Journal of Science, 95:477-80.

COMPTON, J. 1989. The Integration of Research and Extension. In: Compton, J.L (Ed.): The Transformation of International Agricultural Research and Development. Boulder: Lynne Reinner.

CORREA, C.M. 2004. Trade-related Agenda, Development and Equity (T.R.A.D.E). Update on International Developments Relating to the Intellectual Property Protection of Traditional Knowledge including Traditional Medicine. Working Papers. South Centre, Geneva.

CUNNINGHAM, A.B. 1991. Development of a conservation policy on commercially exploited medicinal plants: A case study from Southern Africa. 
IN Akerele, O., Heywood, V. and Synge H. (eds). 1991 The conservation of medicinal plants, proceedings of an international consultation, 21-27 March 1988, Chiang Mai, Thailand. Cambridge: Cambridge University press.

CUNNINGHAM, A.B. \& MBENKUM, F.T. 1993. Sustainability of harvesting Prunus Africana bark in Cameroon: A medicinal plant in international trade. People and Plants Working paper no.2. UNESCO, Paris.

DEPARTMENT OF ENVIRONMENTAL AFFAIRS AND TOURISM, 2004. Government Gazette no. 26436. National Environmental Management Act of 2004. Vol. 467. Pretoria, Republic of South Africa.

DEPARTMENT OF ENVIRONMENTAL AFFAIRS AND TOURISM, 2008. Government Gazette, Regulations no. 8831. National Environmental Management Act of 2004. Vol. 512. Pretoria, Republic of South Africa.

DEPARTMENT OF HEALTH, 1996. The National Drug policy. www.doh.gov.za/policy : [Accessed: 25/09/2006]

DEPARTMENT OF SCIENCE AND TECHNOLOGY (DST), 2004. Policy on Indigenous Knowledge Systems. Pretoria. South Africa.

DEWALT, B.R. 1994. "Using indigenous knowledge to improve agriculture and natural resource management." Human Organization. 53 (2):123-131. Holualoa, Hawaii. USA. 
DOLD,T. \& COCKS, M. 2001. The trade in medicinal plants in the Eastern Cape Province, South Africa. TRAFFIC Bulletin 18: 11-13.

FAROOQUE, N.A \& SAXEN, K.G. 1996. Conservation and utilization of medicinal plants in high hills of the central Himalayas. Environmental Conservation. 23 (1): 75-80.

FLORA, C. \& FLORA, J. 1989. An Historical Perspective on Institutional Transfer. In: Compton J.L (Ed.): The Transformation of International Agricultural Research and Development. Boulder: Lynne Reinner.

GADGIL, M., BERKES, F. \& FOLKE, C. 1993. Indigenous Knowledge for Biology Conservation. AMBIO 22 (2-3): 151-156.

GASENGAYIRE, F. 1999. Workshop on Information Networking on Medicinal Plants and Traditional Medicines in Africa: Towards a Global Strategy. August 2-5, Abidjan report. CRDI/IDRC Regional Office for Eastern and Southern Africa. p121.

GETZ, W.M., FORTMANN, L., CUMMING, D., DU TOIT, J. HILTY, J., MARTIN, R., MURPHREE, M., OWEN-SMITH, N., STARFIELD, A.M., \& WESTPHAL, M.I. 1999. Sustaining Natural and Human Capital: Villagers and Scientists. Science, Vol 283 (5409): 1855-1856. 
GEERTZ, C. 1983. Local knowledge. Further Essays in interpretive Anthropology. New York:Basic Books, p244.

GHAI, D. \& VIVIAN, J. 1989. Grassroots Environmental Action: People‘s Participation in Sustainable Development. UNRISD/Routledge, London.

GRENIER, L. 1998. Working with indigenous knowledge: A guide for Researchers. International Development Research Centre.

HAVERKORT, B., VAN DER KAMP, J. \& WATER-BAYER, A. 1991. Joining farmers' experiments: experiences in Participatory Technology Development. London: ITP.

HOAREAU, L. \& DASILVA, E.J. 1999. Medicinal plants: a re-emerging health aid. Electronic Journal of Biotechnology, Chile.

HORAK, M. 2005. 'Adding value to indigenous knowledge through Scientific Innovation'. International workshop on indigenous knowledge, 9-11 February. Pretoria, Republic of South Africa.

INGLIS, J. 1993. Traditional Ecological Knowledge: Concepts and cases. IDRC Report. Ottawa.

IK NOTES 54. 2003. Traditional medicine practice in contemporary Uganda. World Bank. http://www.worldbank.org : [Accessed 30/08/2006] 
INTERNATIONAL UNION FOR CONSERVATION OF NATURE (IUCN), 2001. Medicinal Plant Conservation. Newsletter of the Medicinal Plant Specialist Group of the IUCN Survival Commission, Vol. 7.

INTERNATIONAL UNION FOR CONSERVATION OF NATURE (IUCN), 2002. Medicinal Plant Conservation. Newsletter of the Medicinal Plant Specialist Group of the IUCN Survival Commission, Vol. 8.

JACKSON, W. 1987. Altars of Unhewn Stone: Science and the Earth. San Francisco: North Point Press.

KALE, R. 1995. South African' health: traditional healers in South Africa: a parallel health care system. Br Med J 310:1182-1185

KAMBIZI, L. 2000. Conservation of medicinal plants in the Eastern Cape Province of South Africa. University of Fort Hare, Alice.

KERWIGI, S. A. 1998. Indigenous Knowledge and The Use of Traditional Medicines in the Rakai District of Uganda. A Paper presented at the Scandinavian Seminar College, Africa Project Workshop, Harare, September 27 - October 1, 1998.

KOTHARI, B. 1995. From aural to written: the documentation of knowledge in Ecuador. In Indigenous Knowledge and Development Monitor. Vol. 3(2) pp 913 
LOR, P. J. \& BRITZ, J. 2004. Knowledge production, international information flows and intellectual property: an African perspective. DATAD Workshop on Intellectual Property, Governance, Dissemination and Funding Strategies, Accra, Ghana. p 16

MAKINDE, M.A. 1988. African Philosophy, Culture, and Traditional Medicine. Monographs in International Studies, Africa Series, No.53. Ohio University. p91.

MANASWE K. (PERSONAL COMMUNICATION) 2005. Understanding and Promoting Traditional Medicine: A journey of correctness workshop. Traditional Health Practitioners Workshop held at Magatle village, Limpopo Province on 22-23 June.

MANDER, M. 1997a. Medicinal plant marketing and strategies for sustaining the plant supply in the Bushbuckridge area and Mpumalanga Province. Nelspruit: DANCED/Department of Water Affairs and Forestry. South Africa.

MANDER, M. 1997b. The utilization of natural resources in Sadiola District, Western Mali: Economic importance and implications for village relocation. Pietermaritzburg: Institute of Natural Resources. (INR Investigation Report no. 155). 
MANDER, M. 1998. Marketing of Indigenous Medicinal Plants in South Africa. A case study in Kwazulu Natal. Food and Agriculture Organization of the United Nations. Rome.

MARSHALL, N.T. 1998. Searching the cure: Conservation of Medicinal Wildlife Resources in East and Southern Africa. TRAFFIC International.

MARULA MARKETING. 2007. General information on the Limpopo Province in South Africa. [online] http://www.marula.co.za/Limpopoinfo.htm. [Accessed: 04/02/2007]

MASOGA, M.A. 2004. Indigenous Knowledge Systems: Issues and Challenges. INDILINGA, African Journal of Indigenous Knowledge Systems. Intellectual Property Rights. Vol.3 No.1. South Africa.

MAUNDU, P., BERGER, D.J., OLE, SAITABAU, C., NASIEKU, J., KIPELIAN, M., MATHENGE, S.G., MORIMOTO, Y., \& HOFT, R. 2001. Ethnobotany of the Loita Maasai: Towards Community Management of the Forest of the Lost Child - Experiences from the Loita Ethbotany Project. People and Plants working paper 8. UNESCO, Paris.

MAVI, S. \& SHAVA, S. 1997. Traditional methods of conserving medicinal plants in Zimbabwe. BGCNews. Journal Archive. Volume 2 Number 8. http://www.bgci.org/worldwide/article/0347/ : [Accessed 22/05/2006] 
MAVI, 1996. Medicinal plants and their uses in Zimbabwe. In: Norman, H., Snyman, I. \& Cohen, M (eds). Indigenous knowledge and its uses in Southern Africa. HSRC- Co-operative programme: Affordable social provision and the Institute for indigenous Theory and Practice. Pretoria, RSA.

MAYENG,I. 1996. Relationship between the sources of traditional and western medicine. In: Norman, H., Snyman, I. \& Cohen, M (eds). Indigenous knowledge and its uses in Southern Africa. HSRC- Co-operative programme: Affordable social provision and the Institute for indigenous Theory and Practice. Pretoria, RSA.

MCKENZI, B., MOERAT, A., \& NAIDOO, D. 1996. Plant collecting for medicinal purpose: It doesn't have to be a problem (a case study of two populations on the Drakenstein mountains). In: Norman, H., Snyman, I. \& Cohen, M (eds). Indigenous knowledge and its uses in Southern Africa. HSRC- Co-operative programme: Affordable social provision and the Institute for indigenous Theory and Practice. Pretoria, RSA.

MEDICAL RESEARCH COUNCIL (MRC). 1997. National Reference Centre for African Traditional Medicines: A South African Model.

MOOCK, J. 1992. Farmers Knowledge and Sustainability. Cornell University Press, Ithaca. pp 1-10. 
MURDOCK, G.P. 1959. AFRICA: Its peoples and Their Culture History. McGraw-Hill Book Co. Inc, New York, Toronto, London. pp 456

NNADOZIE, K. 2004. Policy \& Global Change Series: Trade and Biodiversity. Integrating African Perspectives and Priorities into Genetic Resource Regulations: A Resource Guide for Policymakers, Switzerland. p 9

OLDFIELD, M. 1984. The Value of Conserving Genetic Resources. Washington, D.C., USA; US Department of Interior.

PLANTS OF SOUTHERN AFRICA, 2005: SANBI: htt//p:www.plantzafrica.com: [Accessed: 13/12/2007]

POSEY, D. \& DUTFIELD G., 1996. Beyond Intellectual Property Toward Traditional Resource Rights for indigenous Peoples and Local Communities.; International Development Research Centre, Ottawa, Canada.

POSEY, D. 2000. Cultural and Spiritual Values in Biodiversity. UNEP, Nairobi and Intermediate Technology Publications.

POSEY, D. 2004. Indigenous Knowledge and Ethics; A Darrell Posey Reader. Tylor \& Francis Group Books Ltd. UK.

PRINCIPLE, P.P. 1989. Valuing the biodiversity of medicinal plants. The Conservation of medicinal plants. Cambridge University, Cambridge, UK. 
RAJASEKARAN, B., WARREN, D.M., \& BABU, S.C. 1991. 'Indigenous natural resource management systems for sustainable agricultural development: a global perspective', Journal of International Development 3 (4): 387-402.

RAJASEKARAN, B., \& WHITEFORD, M.B. 1992. "Rice-Crab Production in South India: The Role of Indigenous Knowledge in Designing Food Security Policies." Food Policy 18 (3): 237-247.

RAJASEKARAN, B. 1993. A Framework for Incorporating Indigenous Knowledge System into Agricultural Research and Extension Organizations for Sustainable Agricultural Development in India. Ph.D. Dissertation. Iowa State University, Ames. Iowa.

RICHMOND, B.G \& STRAIT, D.S. 2000. Evidence that humans evolved from a knuckle-walking ancestor. Nature, 404:382-5.

ROSSETTO, M. 2003. The threat posed by habitat loss and degradation. Report of the habitat fragmentation workshop held in Sydney, Australia. http://www.bgci.org/conservation/habitat loss/: [Accessed 07/06/2006]

RUKANGIRA, E. 2001. Overview on the importance and the Status of Medicinal Plants and Traditional Medicine in Africa. Sustainable Development International. Available from: http://www.sustdev.org/features: [Accessed 04/09/2002]. 
SEN, G. 1992. Indigenous Vision: Peoples of India, Attitudes to Environment. Sage Publications, New Delhi.

SHACKLETON, S., SHACKLETON, C. \& COUSINS, B. 2000. Revaluing the communal lands of Southern Africa: new understandings of rural livelihoods. Natural Resource Perspectives 62.

SHANKAR, D. 1998. Foreword. In: Medicinal Plants: A Global Heritage. Proceedings of the International Conference on Medicinal Plants for survival. 16-19 February, Bangalore, India. International Development Research Centre (IDRC), Toronto, Canada.

SLIKKERVEER, L.J. 1989. Changing Values and Attitudes of Social and Natural Scientists towards Indigenous Peoples and their Knowledge Systems. In Indigenous Knowledge Systems: Implicatrions for Agriculture and International Development. D.Michael Warren. L.Jan Slikkerveer. \& S. Oguntunji Titilola.eds. 1989. Studies in Technology and Social Change. No.11. Ames: Technology and Social Change Program. lowa State University.

STATISTICS SOUTH AFRICA, 2001. Census in brief. Pretoria. South Africa.

SOUTH AFRICAN NATIONAL BIODIVERSITY INSTITUTE (SANBI). 2005. Strategic Plan. Overview of SANBI. South Africa. 
SWANSON, T.M., 1992. Economics of a Biodiversity Convention. Ambio 21.3: $250-257$

THRUPP, L.A. 1989. Legitimizing Local Knowledge: "Scientized Packages" or Empowerment for Third World People. Brighton: Institute of Development Studies.

THOMAS, V., GRANT, R. \& VAN GOGH, J. 2002. Sappi tree spotting. Highveld and the Drankensberg tree \& shrub identification made easy. Jacana, JHB, RSA.

UNIYAL, R.C., UNIYAL, M.R \& JAIN, P. 2000. Cultivation of medicinal plants in India. A reference book. New Delhi, India, TRAFFIC India \& WWF India.

VAN STADEN, J. 1998. Biotechnology of Medicinal Plants. Case Studies from South Africa. In Acta Horticulure, 461:87-92.

VAN WYK, B.E., OUDTSHOORN, B. \& GERICKE, N. 2002. Medicinal plants of South Africa. Briza Publications., South Africa.

WARREN, D. M. 1989. The impact of Nineteenth Century Social Science in Establishing Negative Values and Attitudes towards Indigenous Knowledge Systems. In Indigenous Knowledge Systems: Implications for Agriculture and International Development. D.M. Warren. L.J. Slikkerveer \& S. Oguntunji 
Titilola. Eds. 1989. Stusdies in Technology and Social Change. No. 11. Ames: Technology and Social Change Program. lowa State University.

WARREN, D.M. 1991a. Indigenous Knowledge Systems and Development. Agriculture and Human Values 8.

WARREN, D.M. 1991b. Using indigenous knowledge in agricultural development. World Bank Discussion paper 127. Washington DC, USA: World Bank.

WARREN, D.M., \& RAJASEKARAN, B. 1993. 'Putting local knowledge to good use', International Agriculture Development 13 (4):8-10

WENGER, E. 1998. Communities of practice: learning as a social system. Published in the "Systems Thinker". [online] http://www.co-iI.com/coil/knowledge-garden/cop/lss.shtml. [Accessed: 21/02/2008]

WILLAMS, V.L. 1996. The Witwatersrand muti trade. Veld and Flora 82:12-14.

WILLIAMS, V.L., BALKWILL, K \& WITKOWSKI E.T.F. 1996. Risk assessment and the Witwatersrand trade in traditional medicine. Paper presented to the XXII Yearly Congress of the South African Association of Botanists, Stellenbosch, 15-20 January. 
WORLD CONSERVATION MONITORING CENTRE. 1992. Global

Biodiversity: status of the Earth's Living Resources. Chapman \& Hall, London.

WORLD HEALTH ORGANISATION (WHO), 1983. Traditional Medicine and Health Care Coverage. A reader for health administrators and practitioners, p25.

WOLRD HEALTH ORGANISATION (WHO), 2000. General Guidelines for Methodologies on Research and Evaluation of Traditional Medicine. Geneva.

WORLD HEALTH ORGANISATION (WHO), 2002. WHO Traditional Medicine Strategy 2002-2005. World Health Organisation. Geneva.

WYNBERG, R. 2002. A decade of biodiversity conservation and use in South Africa: tracking progress from the Rio Earth Summit to the Johannesburg World Summit on Sustainable Development. Review Articles. South Africa Journal of Sciences 98. p233.

ZHANG, X. 2004. Traditional Medicine: Its Importance and Protection. The role of Traditional Knowledge in Healthcare and Agriculture. In: Twarog S and Kapoor, P. (eds.). Protecting and Promoting Traditional Knowledge: Systems, National Experiences and International Dimensions. United Nations Conference on Trade and Development. New York and Geneva. 
APPENDIX A: INTERVIEW SCHEDULE/LETLAKALA LA DITSHWAOTSHWAO

1) Traditional Health Practitioners' practices - which parts of the plant are used for medicinal purposes?

2) What are problems, opportunities and challenges of harvesting medicinal plants from the wild?

3) Give three types of medicinal plants which are scarce/extinct/overharvested or needed but not easily found in your area.

4) Which species are of particular concern and should be given priority for positive action?

5) What are causes behind depletion of wild population of medicinal plants situation?

6) What can be done to ensure the effective conservation of all medicinal plant species?

1) Mešomo ya dingaka tša setšo - ke karolo efe ya mohlare yeo o e šhomišetšwago kalafi?

2) Ke mathata, ditšhono le dikgwethlo dife punong ya dihlare tša kalafi ka shokeng?

3) Efa mehuta e meraro ya dihlare tšeo di nago le khuetšo ya thlokego mo lefelong la lena?

4) Ke mehuta efe ya dihlare yeo e nyakago thlokomelo.

5) Ke eng tšeo di dirago gore dihlare tša kalafi di nyamele?

6) Ke eng seo se ka dirwago go shireletša dihlare tša kalafi kamoka? 